\title{
Agile Manufacturing from a Statistical Perspective
}

Robert G. Easterling New Initiatives Department Sandia National Laboratories Albuquerque, NM 87185

U.S. DEPARTMENT OF COMMERCE Technology Administration National Institute of Standards and Technology

Statistical Engineering Division Gaithersburg, MD 20899

QC 100 .056 



\section{Agile Manufacturing from a Statistical Perspective}

Robert G. Easterling New Initiatives Department Sandia National Laboratories Albuquerque, NM 87185

U.S. DEPARTMENT OF COMMERCE Technology Administration National Institute of Standards and Technology

Statistical Engineering Division Gaithersburg, MD 20899

October 1995

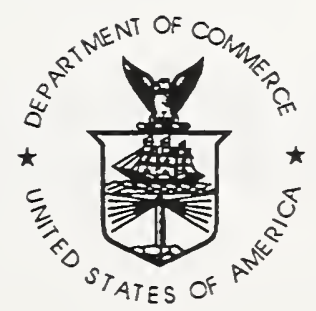

U.S. DEPARTMENT OF COMMERCE Ronald H. Brown, Secretary

TECHNOLOGY ADMINISTRATION

Mary L. Good, Under Secretary for Technology

NATIONAL INSTITUTE OF STANDARDS

AND TECHNOLOGY

Arati Prabhakar, Director 

NISTIR 5573

\title{
AGILE MANUFACTURING FROM A STATISTICAL PERSPECTIVE
}

\author{
Robert G. Easterling* \\ New Initiatives Department \\ Sandia National Laboratories \\ Albuquerque, NM 87185
}

\begin{abstract}
The objective of agile manufacturing is to provide the ability to quickly realize high-quality, highly-customized, in-demand products at a cost commensurate with mass production. More broadly, agility in manufacturing, or any other endeavor, is defined as change-proficiency -- the ability to thrive in an environment of unpredictable change. This report discusses the general direction of the agile manufacturing initiative, including research programs at the National Institute of Standards and Technology (NIST), the Department of Energy, and other government agencies, but focuses on agile manufacturing from a statistical perspective. The role of statistics can be important because agile manufacturing requires the collection and communication of process characterization and capability information, much of which will be data-based. The statistical community should initiate collaborative work in this important area.

* This work was performed while the author was a Visiting Researcher at the Statistical Engineering Division, National Institute of Standards and Technology, Gaithersburg, MD. The report will also be published as a Sandia report, SAND95-1552
\end{abstract}





\section{TABLE OF CONTENTS}

INTRODUCTION AND SUMMARY ...................................................................................................... 4

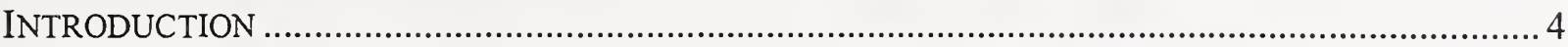

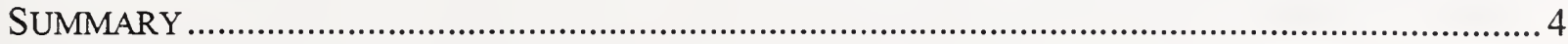

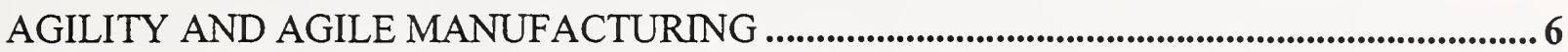

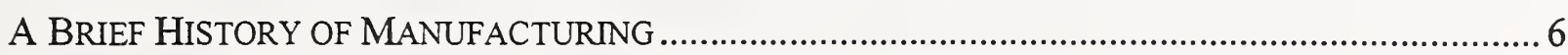

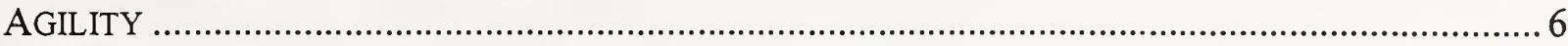

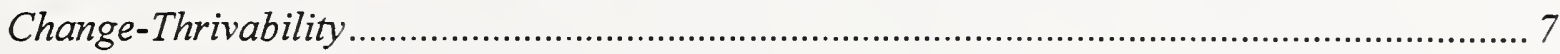

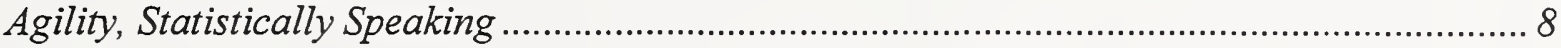

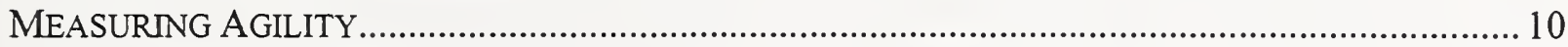

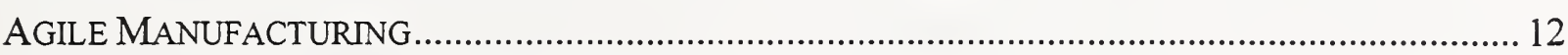

MANUFACTURING PROCESS MODELING..................................................................15

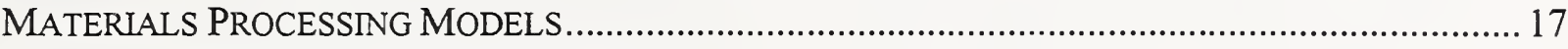

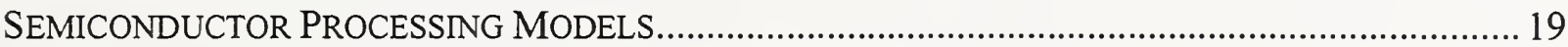

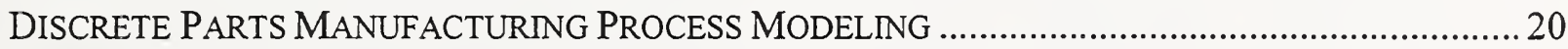

PROCESS MODELING: STATISTICAL CONSIDERATIONS......................................................20

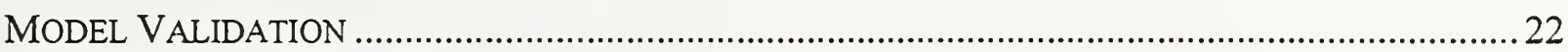

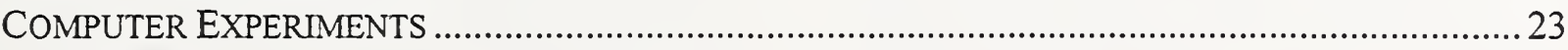

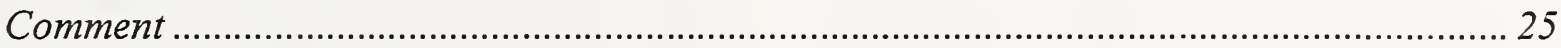

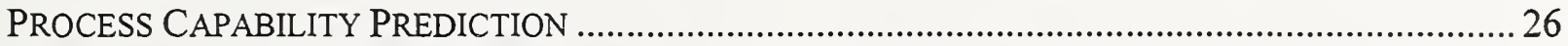

Process Capability Prediction Based on Physical Experimentation......................................22

Process Capability Prediction Based on Mathematical Models …………………………. 27

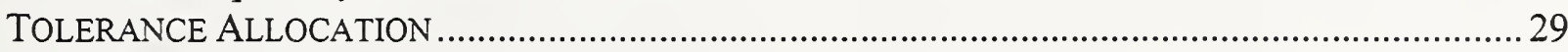

AGILE MANUFACTURING AND QUALITY ..............................................................................29

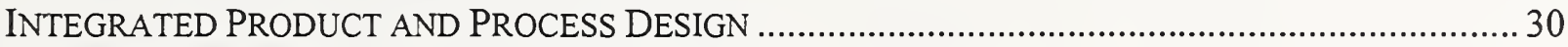

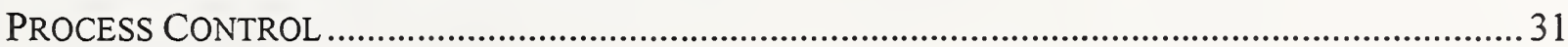

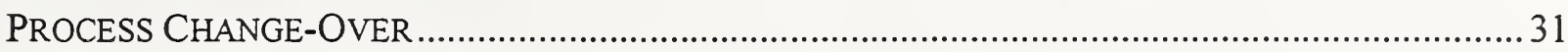

SHORT-RUN PROCESS CONTROL ………………………............................................. 31

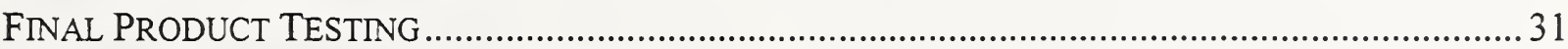

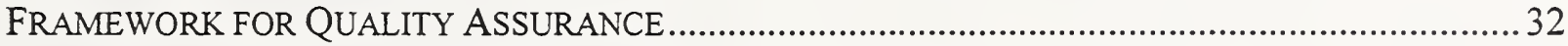

THE AGILE MANUFACTURING RESEARCH AGENDA .......................................................33

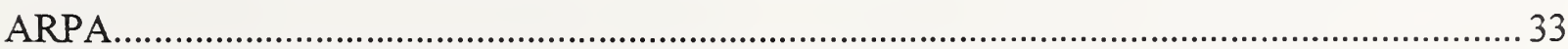

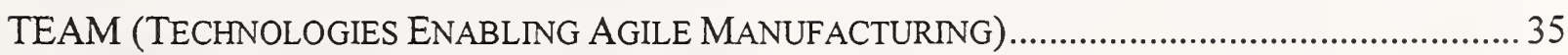

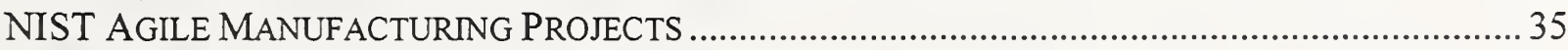

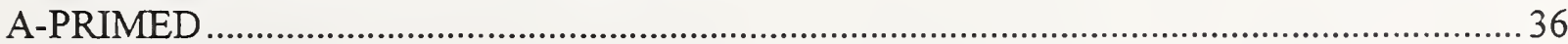

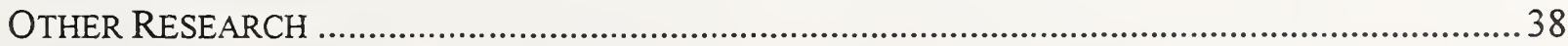

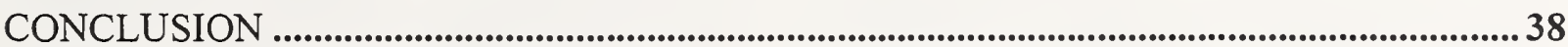

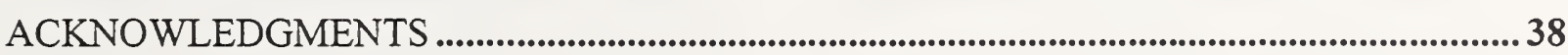

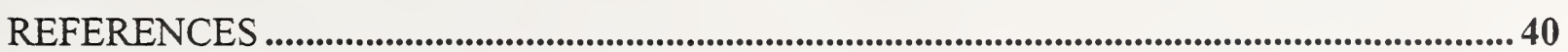





\section{AGILE MANUFACTURING FROM A STATISTICAL PERSPECTIVE}

\section{INTRODUCTION AND SUMMARY}

Introduction

Agile manufacturing, and, more generally, agility, have become topics of considerable interest to industry -- a source of ideas, conferences, organizations, and funding. Agility is broadly defined by the Agility Forum (an industry-led, government-funded organization established by the Iacocca Institute at Lehigh University) as the ability to thrive in a continuously changing, unpredictable environment (Dove 1994), More concretely, agile manufacturing is thought of as the ability to quickly realize (design, produce, and deliver) totally new, customized, high-quality products at prices commensurate with mass production. To accomplish this, a structure that is envisioned is a "virtual enterprise" in which various resources, or processes, are linked, sometimes across corporate lines, in a type of partnership that goes beyond traditional supplier-producer relationships.

Agility, as "change-thrivability," is obviously a desirable ability, from the personal to the organizational to the corporate to the national levels. Nobody could be against it. The challenge is how to achieve it. The virtual enterprise is seen as an important ingredient. But of course there are other possible success ingredients, such as flexibility, leanness, total quality management, process re-engineering, customer-focus, and many others. And as a statistician, I think overt statistical thinking and methods -- data-driven decisionmaking, ferreting out and eliminating or controlling sources of variability, etc. -also enhance an enterprise's chance of success or its thrivability in the face of change. With this motivation, then, I decided to explore the concept of agility and the possible role of statistics in agility.

Many authors have written on statistical needs in industry (see, e.g., Hoerl et al. 1993 and their references), with an emphasis in recent years on the relationship of statistics to quality. There are other aspects of industry that warrant statistical participation, one of which potentially is agile manufacturing. Thus, the focus of this report is the potential role of statistics as an enabler of agile manufacturing. Whether or not Total Quality Management in its various incarnations fades from the limelight in favor of something else, say reengineering, or maybe even agility, the constant need remains for statisticians to help industry make better products, more consistently, quickly, and economically. Useful, usable data-based information is essential to good industrial practice, under any banner, and that need provides opportunities for statistics.

\section{Summary}

The broad, current definition of agility as thriving on unpredictable change has led to the development, by the Agility Forum, of a structure, or a framework, for addressing "change-proficiency." Change-proficiency is not a characteristic limited to virtual enterprises, so this structure can apply to individual organizations, product lines, or work stations. Change-management is a recurring theme in industry, with an extensive literature, so it remains to be seen whether the agility perspective will $b$ ring something new to change-proficiency.

But, what is the agility perspective? What does one do to become agile? By the broad definition, anything that works (thrives on 

change) must be agile. Thus, widely disparate examples of successfully dealing with unpredictable change, with no other constraints, are not very helpful. For example, an agility instance I have seen cited is the hiring by one company of a $\mathrm{CEO}$ from an unrelated industry. The structure developed by the Forum for evaluating an operation's changeproficiency in various domains, plus the development of reference models of "best agile practices" should help define agility in practical ways.

In statistical terms, agility is a dependent variable. Development of a theory of agility means the identification of predictors of agility -- industrial practices that increase the probability of thriving in an environment of unpredictable change. Examples and case studies can suggest predictors, but caution is warranted in inferring a cause-and-effect relationship in such observational data. What works for one company in its environment may not work at all for another company and its environment. Ideally, one would test theories in controlled experiments, but company-level, or product line-level experiments are generally infeasible. Government funded research could undertake such experiments.

Change-proficiency theories can be interesting, but the real opportunities for statistics lie in agile manufacturing -- quick realization of high-quality, highly customized products, at competitive cost. Predictable, well-characterized, and wellcontrolled manufacturing processes are required in order to rapidly reconfigure manufacturing processes to produce products that meet particular customer needs, and much of the process information required to support successful reconfiguration will be statistical in nature. Mathematical models of processes are needed in order to make design and production process decisions much more rapidly than can be done by iterative physical testing. While these models are often physics-based, there are statistical issues in the estimation of model parameters and in the validation of models experimentally. Agile design decisionmaking, however, may require models of relationships that are not typically addressed theoretically, so the development of empirical models is also needed, a point that has been made in the materials processing area by Szekely and Trapaga (1994). A NISS (National Institute of Statistical Sciences)-NIST workshop report (Karr 1994) points further to the opportunities for statistical-materials sciences collaboration in developing the process understanding and analytical tools that will permit agile manufacturing. The availability of computer models and the need to extract information from them lead to computer experiments and raise experimental design issues that the statistical community has been addressing in recent years. Predicting process capability via process models, as opposed to process exercising, also poses interesting statistical problems.

Much industrial statistical practice is quality-related and the national quality thrust of recent years has invigorated industrial statistical practice. Quality is one element of agile manufacturing -- it's assumed that high-quality will be achieved. Actually accomplishing that, in the dynamic, short production run (lot size of one?) world of agile manufacturing will require the (continued) development and application of new statistical methods. It is also apt to require deep immersion by statisticians in product realization projects, rather than the role of a consulting specialist. The goals of agile manufacturing -- faster, better, cheaper -- extend beyond the traditional bounds of quality, say process characterization and control, 

and they will endure, whether under the heading of agile manufacturing or some other banner. Statisticians and statistical methods can make important contributions to achieving these goals.

Research under the heading of agile manufacturing generally deals with the infrastructure for linking together the processes required by an enterprise and for moving information across those connections. Presently, there seems to be little statistical content in infrastructure issues, but at some point standards for the transmittal of statistical information pertaining to processes will become important. A Sandia demonstration project, though, has provided an opportunity for the development and testing of statistical qualification methods in agile manufacturing.

The goal of agile manufacturing -- quick, economical realization of high-quality, customized product -- is important to industrial competitiveness and survival. The routes to that goal may differ from industry to industry and company to company. Common to all, though, is the need to provide information that can be readily used to decrease design and production time and cost. Modern data generation, storage, and analysis capabilities pose new problems and opportunities for the statistical extraction of information from data. But, the opportunity has to be seized. Statistics can be (or at least perceived to be) a speed-bump rather than a speed-enhancer on the road to progress. Our personal and professional agility are worth some thought.

In sum, I encourage statisticians to seek out collaborative opportunities to help industry realize the goals of agile manufacturing. This report describes in general the sort of work that is needed, but it is the day to day, in-depth project involvement that will lead to success.

\section{AGILITY AND AGILE MANUFACTURING}

\section{A Brief History of Manufacturing}

A century ago, manufacturing was accomplished by craftsmen. A single craftsman made a rifle; a team of craftsmen made a locomotive. Then, to meet the needs of mass production, came interchangeable parts (achieved by variance reduction) and the assembly line. Straight line production is susceptible to bottlenecks and breakdowns, so flexible manufacturing systems evolved, whereby alternate paths through a production network were possible. Leanness in manufacturing has to do with the elimination of waste and nonvalue-adding operations (which can also be variance-introducers), and can be related to flexibility. If a machine, or work cell, or technician is flexible enough to do more than one job, the operation is leaner because of not having to have two dedicated machines. (Reader's Digest joke: To the old saw about how the optimist and pessimist see the half-full (-empty) glass of water, there is added the efficiency (reengineering, lean, ... ) expert who says, "Whoa. Looks like you've got twice as much glass as you need.") Agility, then, is to be the next step beyond flexibility.

\section{Agility}

(This discussion is drawn largely from Nagel and Dove (1991) and Dove (1994) plus my experiences as a member of the Agility Forum's Agile Operations Focus Group. Dove (1995), which appeared after this report was largely written, is the 

Forum's most recent exposition on agility.) The vision set forth (Nagel and Dove 1991) by the team that launched the agile manufacturing initiative is that the agile enterprise will be able to rapidly create totally new products, not just flexibly produce a particular product. Stated more fully, the agile enterprise will quickly produce high quality, highly customized products, usually in low volume, at the same cost levels achievable by mass production. The phrase sometimes used is "mass customization." Horse shoes one day; engine blocks the next. Further, in some contexts, the product is to be readily upgradeable in the hands of the customer, a la some computers. All this is to be achieved by linking together resources and processes, oftentimes across corporate lines, thus forming a "virtual enterprise," supported by an information infrastructure and system of standards that smoothly accomplish the linkage and implemented by a workforce that correctly and efficiently uses and communicates the information made available, to produce a customized product. Then, after delivering the product, the enterprise will dissolve and reform in other configurations to produce other products. To a degree, the concept of mass customization is a return to craftwork (Headline, Wall Street Journal, Oct. 24, 1994: "Back to the Past: Some Plants, Especially in Japan, Are Switching to Craft Work From Assembly Lines"), but on a larger scale and with more fluidity and speed.

Agility in manufacturing is not explicitly defined in Nagel and Dove (1991). Thus, the implication is that the dictionary definition applies: agile -- "marked by ready ability to move with quick easy grace;" agility -- "nimbleness, dexterity" (Webster's Ninth New Collegiate Dictionary). Subsequent work on developing the concept and providing the credentials for a new paradigm, represented by Dove $(1994,1995)$, has led to the greatly expanded definition given above: ability to thrive on unpredictable change. The apparent connection is that in order to thrive on unpredictable change, an enterprise must be able to rapidly create totally new products (as opposed to rapid improvements or modifications of existing product lines). This ability is to be derived from the ability to quickly reconfigure processes and resources to achieve creation of a new product ("reconfigurable everything" is the phrase used). Further, agility, under the broad definition, is not restricted to manufacturing and it can be applied to various levels within an enterprise -- a department, a machine, a product line, a service organization -- and not just to a cross-corporate virtual enterprise.

\section{Change-Thrivability}

Companies have always had to deal with changing environments -- buggy-makers became automobile makers; some thrived, most disappeared. Management texts and journals must, I would guess, be filled with case studies and theories of success. Currently, U.S.-Asian joint ventures in automobile production are examples of reconfigurability as a survival/thrival technique. Whether the current rate of change, or the nature of current changes, is dramatically different from the past, as advocates of agility and other avenues to success maintain, and render earlier solutions inadequate, is an issue that I'll leave to the specialists. There is always a tendency, though, call it proximity bias or short-term memory, to regard the present environment as dramatically more challenging than anything our predecessors saw and therefore there is a need for new solutions. 

Whatever the nature and pace of change, today's businesses need to deal with today's changing environments. How do they do it? Is there any underlying theory of thrivability? Are there tools that help 'do agility'? What changes should be made on the factory floor? Several years ago there was a spate of books on change management, but these seem focused on the sociological aspects of adapting to or surviving change that is thrust upon one, or they dealt with the methods by which an enlightened or frightened management could bring change to their organizations. The current hot management topic, reengineering, continues the change theme and deals with radically changing internal processes and often reducing the workforces that run those processes. (A changesurvival approach that appeals to me, which is the bane of change-theorists, but will someday have its 15 minutes of fame, is the science of 'muddling through,' which I once saw in an article -- British, I believe.)

The agility proponents appear to be broadening the change-management perspective by considering the technical aspects of change -- how do you design a system, or a company, or a department to be change-proficient? -- and going beyond survival to "thrival." Also, rather than the ability to make a specific change, the agility focus is on the ability to respond to future, unanticipated, repeated changes in the environment. But even if there were nothing new in the objective of changeproficiency, in a dynamic world there is need to rethink change as the times change. For example, computing and communications power, the ability to rapidly generate, process, and exchange massive amounts of information (not just data), is both a part of today's unpredictably changing environment and a provider of the technological tools that make new modes of change-proficiency possible. So, new tools for change-proficiency are available and agility provides a vehicle for their application. Agility, as change-proficiency, is in an early stage of development, and it remains to be seen whether this perspective will add to our understanding of change.

\section{Agility, Statistically Speaking}

Agility, in statistical terms, is a dependent variable, a response variable, not a set of independent variables that "causes" this response. Its definition doesn't provide or suggest the means by which that result is to be attained. The leading candidate independent variable, by the discussion above, is reconfigurability: "Reconfigurable everything" (it is said) leads to the ability to thrive in an environment of unpredictable change. But, that's a difficult theory to test and to put into practice and one can conjecture about other causal, or at least contributing variables, such as concurrent engineering, computer-aided everything, automation, visionary leaders, flat management structures, empowered work teams, and many more. The definition of agility invites such conjectures. Sorting it all out, finding methods that, in advance, can be claimed to have an appreciable probability of success, is an objective of the Agility Forum and agility research sponsors. To date, the search for independent variables has led to the collection of examples and the development of "reference models," which are collections of best agile practices, and to a focus on smaller organizational units than a virtual corporation.

The breadth of the Agility Forum definition of agility can lead to putting everything good under the heading of agility (if it works, it's agile). Doing so, though, dilutes the concept and confuses people trying to understand what is new and unique about agility. More specific examples can help to characterize agility in practice and one can 

also examine collections of examples to try to identify common contributors to agility. While such information can be useful, the (statistical) cautions one should apply to observational data are very appropriate. Just because Company A attributes its success on Project $P$, in environment $E$, to its use of method $X$, doesn't mean that Company $\mathrm{B}$, in environment $\mathrm{F}$, can expect success if it uses method $\mathrm{X}$. Either 'lurking,' unrecognized or unattributed variables, by themselves or in conjunction with method $\mathrm{X}$, or environmental differences may invalidate such an inference. A familiar example is that some American companies found that some Japanese quality practices were not a "treatment" that could be applied to their company and get the desired response. The "Hawthorne effect," improvement due just to the attention given a project, rather than the method tested, may also be at work.

Further, there is a selection bias: we don't know how many other companies tried method $X$ and were not successful. Typically, the search for examples begins with a survey asking for success stories and typically the response rate is very low, clearly a further source of selection bias. In reliability terms, success stories provide numerator data, not denominator data, so probability of success cannot be estimated. Lack of a control (e.g., a parallel project that used method $\mathrm{Y}$, a standard method) and lack of replication also limit the ability to draw inferences from examples.

One way to overcome the limitations of observational studies would be to conduct designed experiments, but that is generally not feasible in a commercial manufacturing setting. For example, it's generally not possible to have two or more teams take on the same project by different methods. All one can often do when a new approach is tested, is to measure its value by comparison to a previous project under the old approach. Reduced cycle times, costs, etc., if achieved, are attributed to the new approach. Some sort of subjective standard error is used to decide when the reduction is more than just (random) noise. This attribution may be warranted at least in part, but separating out the method's effect from general learning effects and the Hawthorne effect may be impossible. In these circumstances, face validity of anecdotal evidence is generally what one has to rely on in inferring the success of a new method. If multiple companies (or a whole country, say Japan) replicate tests of method $\mathrm{X}$, then the combined results should be more convincing (providing nonsuccesses are not screened out). I'm not aware (not having searched the management literature) whether any such meta-analyses have been carried out. In this vein, though, recent news stories reported a follow-up study of companies identified in the Peters and Waterman (1982) book, In Search of Excellence, that found their stock performance had not exceeded overall stock averages. While stock performance may not be the best measure of excellence, the notion of looking for consistent effects across multiple "trials" of a method is statistically correct. Both the average and the variability of those effects are informative. To some extent government- and industryfunded work in industry, university, and government laboratories, taken together, is an experiment in agility methods. Looking at that program from an experimental design point of view (Are there controls, replication?) might be informative.

It is interesting to contrast the way in which new industrial procedures are adopted with the way in which new medical procedures are adopted. Medical procedures require fairly strong experimental proof of efficacy and the lack of harmful side effects. Industrial/management procedures require publicity, charismatic advocates, and a 


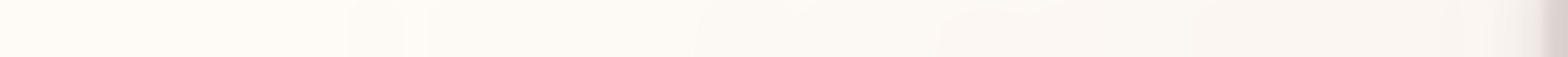


good collection of anecdotes. Experimenting on companies, or product lines within companies, is different from experimenting on patients, but the similarities, and differences, and the benefits provided by clean experimental evidence are worth thinking about.

Examining sets of examples and identifying common apparent contributors to success is sometimes called 'benchmarking.' I'm aware of two agility benchmarking studies: One, by the Agility Forum (Goldman 1992) selected four characteristics of agility: information-sharing, man-machine interface, concurrency, and level of cooperative development across companies, and asked companies to compare successful and not so successful projects with respect to these characteristics. Contributing factors to success were identified as: simulation/ modeling techniques, design technologies, flexible production techniques, and information technologies. Another benchmarking study, Hilton and Gill (1994) attributed leading companies' success in quickly and efficiently launching new products to the "use of cross-functional teams, a standardized development process, and a partnership approach to supplier management" -- not exactly the dramatic stuff of a new paradigm. Further study would be required to tell whether consistent evidence on the contributors to agile success was found in the two studies.

Another means by which the concept of agility is being developed is by focusing on smaller units than the cross-corporate virtual enterprise. A work cell, a product line, a business system, a department, etc., can all have features that allow them to thrive in a changing environment. One can also have temporary organizations created within a corporation. While this would just be a project team, hardly a new concept, agility ideas may have something to offer in how those teams are created, supported, and managed. To characterize agility at these lower levels, the Agility Forum is sponsoring focus groups that will collect best practices in very specific areas and assemble them into "reference models" of agility. Further, as described in the following paragraphs, it is defining "best" from an agility perspective, which is not necessarily the same as, say, a profitability perspective. Where best practices are not very agile, constructs of what would be agile will be developed. For these reference models to be useful it will be necessary, following the discussion of the previous paragraphs, to provide as much information about the environmental context as possible, and to probe these best practices for hints of lurking variables. (Note. My cautionary remarks are not meant to discourage learning from others' experience -- what are the alternatives? -but to point out ways in which that learning might be enhanced.)

\section{Measuring Agility}

Dove (1994) has initiated the development of a structure, a set of principles underlying agility, by identifying domains in which an organization has to be proficient at change. That is, to thrive in an environment of unpredictable change, an organism has to be proficient at changing itself to cope with and capitalize on environmental change -industrial Darwinism or Lamarckism, if you will. (Actually, agility advocates say that adaptation won't keep up; DNA alteration is needed.) At any rate, eight change domains have been identified and are listed in Table 1. The terminology in Table 1 requires some elaboration. I would express the Table 1 domains, in general terms, by saying that you have to be proficient at changing what you produce, how much you produce, the configuration of your processes and resources, your resource mix, and your fundamental concepts; further, 

your processes have to be robust, fixable, improvable, and improving. Reusable, reconfigurable, and scaleable are other adjectives that reflect agility's attributes (Dove 1995).

To evaluate change-proficiency in these domains, it is proposed to measure proficiency in four dimensions: 1. Cost. 2. Time (How much money and time does it take you to change, in response to some specified environmental change?). 3. Robustness (For example, when a change is made from one product to another, how much effort and cost are required to get the new product line running smoothly?).

Table 1. Eight Agile Change Domains*

\begin{tabular}{|c|c|}
\hline Creation & Build something new. \\
\hline Capacity & $\begin{array}{l}\text { Increase/decrease existing resource } \\
\text { mix. }\end{array}$ \\
\hline Capability & Add/delete resource types. \\
\hline Reconfiguration & $\begin{array}{l}\text { Change relationships among } \\
\text { modules }\end{array}$ \\
\hline Migration & $\begin{array}{l}\text { Event-based change of } \\
\text { fundamental concepts. }\end{array}$ \\
\hline \multicolumn{2}{|c|}{$\begin{array}{l}\text {...Agile adds new domains above to traditional lean } \\
\text { domains below }\end{array}$} \\
\hline Performance & Real-time operating surprise. \\
\hline Improvement & Continuous, incremental upgrade. \\
\hline Recovery & $\begin{array}{l}\text { Reincorporate corrected failures or } \\
\text { altematives. }\end{array}$ \\
\hline
\end{tabular}

*Copyright 1994, Rick Dove, Agility Forum, Bethlehem, PA 18015

4. Scope (How much change can you cope with (thrive on?)). These dimensions are intertwined, of course, and the first three are functions of the magnitude of the change that is postulated. For example, a composite-material bicycle wheel maker might be asked to consider the changes required to: 1. make wheels with slightly larger or smaller diameters, 2. make composite-material tennis rackets, or 3. make composite-material auto body parts. Or, since we're talking total unpredictability here, 4. to make plastic trash cans, or 5. space shuttle skin panels. Time, cost, and robustness will vary with the contemplated change, so there's no single measurement of these attributes. Scope, though, should limit the postulated change to changes within reach of an organization's competencies and resources, which puts a practical limit on the unpredictableness of the change that can be considered. That is, "Horseshoes today. Engine blocks tomorrow," may be the epitome of agility, but it is beyond practical planning horizons.

This categorization of change domains and metrics, under the working hypothesis that change-proficiency leads to thrivability, translates the focus to specific, measurable (in principle) characteristics, as does, e.g., defining cardiovascular health in terms of blood pressure, cholesterol, triglycerides, etc. These 32 attributes are still dependent variables, but by being more specific and measurable, in principle, the search for independent variables that influence selected attributes may be simplified.

The matrix structure consisting of change domains by dimensions can also be used to evaluate an operation's agility. Considering the enterprise as a whole, Dove (1994) suggests 12 "enterprise elements" within which such an evaluation might be done, but it's possible to apply the analysis to any organizational unit. Doing such evaluations has been one function of the Agility Focus Groups. From limited experience, my impression is that this analytical tool has not yet been developed enough to say that the agility perspective yields insights not otherwise obtainable. Asking a bicycle wheel manufacturer to think about making tennis rackets may not stimulate much insight. Experienced, knowledgeable reviewers, whether thinking agility or not, can usually spot problem areas in a 

production process, including areas that are lacking in or degrading to changeproficiency, but these are apt to be wellrecognized by members of the organization being reviewed.

(As a personal aside, I would note that while the activities of the Agile Operations Focus Group in which I have participated have had limited explicit statistical content, this participation has been very valuable in providing a context in which to examine statistical aspects of agility. It is also useful, I think, to examine one's personal and organizational skills in terms of proficiency in the various change domains. Statistical practice has some inherent agility skills in that statisticians can be quickly reconfigured. We can plug our methods into a wide variety of applications (enterprises). One of my professors, Carl Marshall, expressed the following sentiment which has remained with me: "The nice thing about statistics is that the nouns may change, but the verbs stay the same." That is, bushels of corn one day, microelectronic chips the next, but ANOVA (analysis of variance) endures.

(Organizationally, though, we need to pay attention to our change-proficiency. We face unpredictable changes in the environments in which statistical organizations function. Companies and agencies can suddenly reorganize in ways that can profoundly alter the working relationships and clientele that a statistical organization has established. The quality boom provided a boost for some statistical groups, witness the various university Quality Centers that sprang up, but what next? Recent AmStat News articles have discussed with alarm the dissolution of and attacks on institutional statistical groups.

A full airing of these issues is outside the scope of this report, and I can offer no solutions except to note that, as an inherently collaborative discipline, the agility model of floating alliances is appropriate. We need to initiate, establish, and contribute importantly to alliances in emerging areas, such as the subject of this report, agile manufacturing.)

\section{Agile Manufacturing}

Outside the Forum, agility in manufacturing (or, agile manufacturing), I believe, is generally still defined, in line with the original Agility Forum vision (Nagel and Dove 1991), as the ability to quickly realize highly customized, high-quality product, generally in low volume, but at a cost corresponding to mass production. (I don't think, however, that the condition that this product literally be "totally new" is imposed. You've got to stay within reach of your core competencies, which, of course, can change over time.) This definition, which is recognizably related to the dictionary definition (nimbleness), translates more readily (than change-thrivability) into engineering approaches such as concurrent engineering, the use of mathematical models and computer simulation to reduce design and test times, technology improvement, automation, and real-time process monitoring and control. Improved manufacturing architectures, such as flexibility and reconfigurability, also fit in here. Of course, technology does not exist in a vacuum, so the surrounding and sometimes supporting business, engineering, and cultural practices are also important contributors to product realization and they need to be designed to facilitate the speed and cost-effectiveness of the endeavour, i.e., to be agile. All this is evidence of change-proficiency, but is not tantamount to it.

The balance of this report will focus on agile manufacturing as rapid, customizedproduct realization. In the preceding pages, 

I've dealt at some length, however, with agility in the broad sense, because that is the direction the agile manufacturing initiative has moved. And it does provide an appropriate backdrop: rapid realization of customized products will require changeproficiency. I'm concerned, though, that rapid (customized) product realization, reconfigurability, and change-thrivability are all getting so mixed up that the concept of agile manufacturing will suffer because of it.

Reducing product realization cycle times and costs, from concept to delivered product, has long been an imperative for industry and will continue to be, whether under the heading of agile manufacturing, quality improvement, re-engineering, or something else. While some industries may survive, even thrive, for some periods of status quo operations ("If it ain't broke, don't fix it."), competition generally disrupts this state of complacency. If there is a constant, it is the need for improvement. And, as long as some fraction of the population has enquiring minds and tolerant management, people will seek better ways of doing things, some evolutionary, some revolutionary. Agile manufacturing continues the industrial imperative for reduced product realization time and costs and adds the imperative for customized, economical, low-volume production.

On the matter of terminology, it may be useful to distinguish between advanced manufacturing and agile manufacturing. Advanced manufacturing, in my understanding, refers to the new technologies -the processes and equipment -- by which raw materials are transformed into products. Clearly, new manufacturing technology is often aimed at faster product realization, reduced cost, and higher quality -- less time, less rework, less variability -and so it contributes to agile manufacturing. Agile manufacturing, though, refers to the coordination of manufacturing technologies (not all of which need be considered "advanced") in order to rapidly realize customized product. It also refers to the supporting mechanisms and business and engineering practices by which this can smoothly happen. For example, data bases and software support systems that help a design team quickly and intelligently choose among design options are contributors to agile manufacturing.

Figure 1 is my depiction of agile manufacturing. At the upper right of the figure is the enterprise's objective -- a product aimed at satisfying a customer's requirements in terms of cost, performance, production-volume, and schedule. Producing that product requires the linkage of several processes. The figure illustrates a serial linkage, in which the output of each process is input, possibly along with other inputs, for the next process. More complex arrangements are, of course, possible.

Next, Figure 1 shows that for each process, the producer, conceptually, has various alternatives from which to choose. These alternatives could be different equipment, different parameter settings on the same equipment, different potential partners (in the sense of forming a virtual enterprise), distinctly different processes (such as the use of different chemicals in a cleaning process), etc. The decision problem is to choose among the alternatives for each process in order to yield a product that meets or exceeds customer requirements in performance, cost, volume, and schedule. The agile challenge is to make these decisions quickly and intelligently (right, or nearly right, the first time). Achieving this means having viable choices at your disposal and having enough information about them to make good choices. Making different choices for different products and customers represents the reconfigurability discussed above. 

As indicated, meeting the agile manufacturing challenge requires information -- a lot of information, but not so much as to overload the recipient's capacity and not so overladen with noise that the signal is obscured. It is the generation and management of appropriate information that is the backbone of agile enterprises. One will not have the luxury of developing new processes, evaluating and comparing

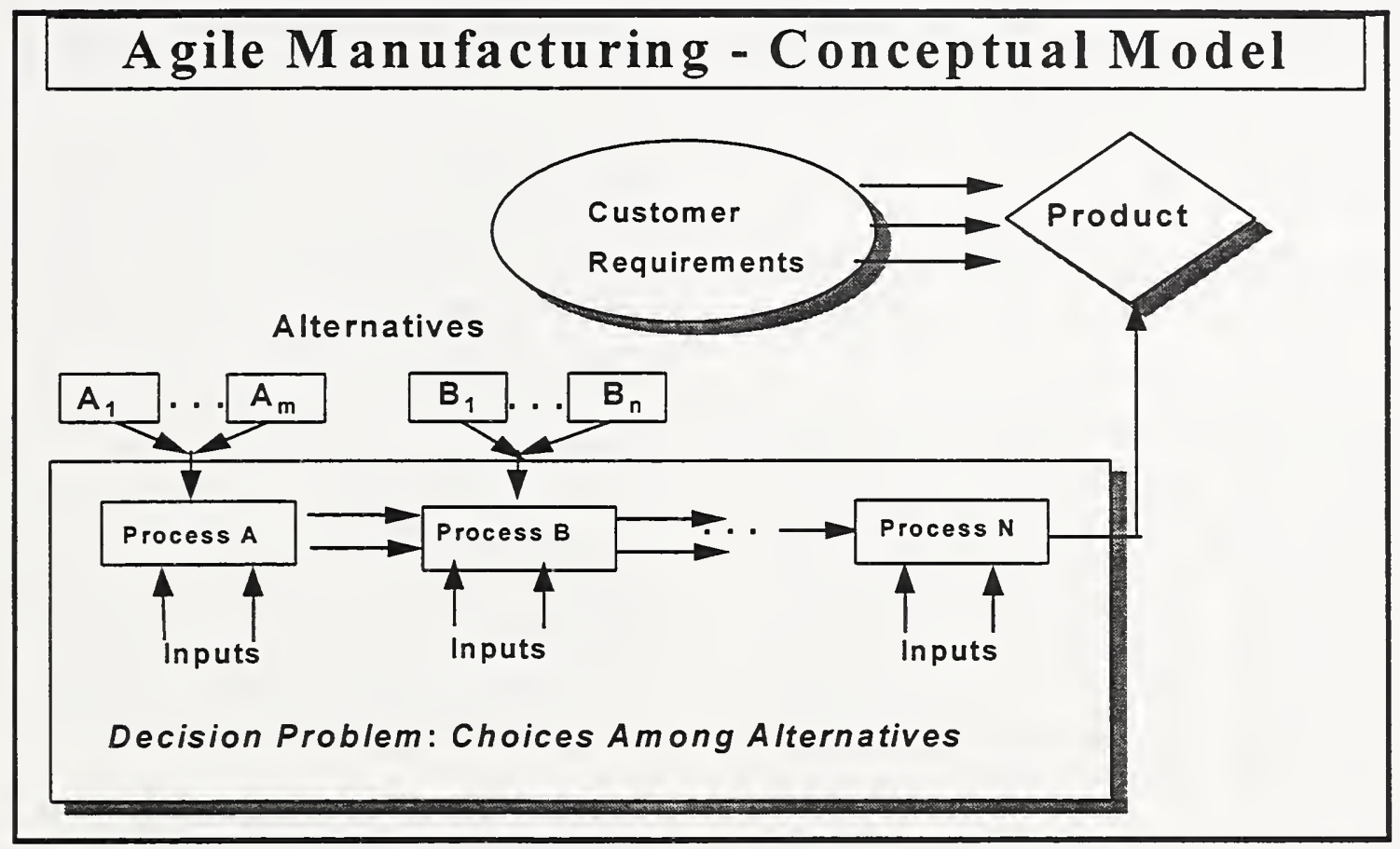

Figure 1. Conceptual Model of Agile Manufacturing

alternatives, then designing, building, and testing prototypes for several iterations until arriving at a successful product design. Instead, one needs readily available and understandable information pertaining to the alternative processes and their interfaces, plus the ability to predict the characteristics of the product that will emerge from a selected candidate set of processes. Good, trustworthy predictions would mean that few, if any, prototypebuild and design-tweaking iterations would be required before actual production.

Morton (1994) in a wide-ranging and entertaining survey of manufacturing technology, published in The Economist, cites agile manufacturing as "(o)ne of the most influential visions of future manufacturing in the past few years," and describes the importance of predictability in the following terms:

The precondition (to agile manufacturing) that matters most ... is predictability. The essence of agility is sensitivity to time. The different companies involved have to know their capabilities exactly, and the time they take exactly. This is what new factory management technologies make possible. When a virtual enterprise is assembling itself, it has to know 

precisely the dimensions of its parts, not in breadth, length, and depth, but in terms of such things as process time and quality. At present, few companies can accurately measure themselves in many of these dimensions.

One might statistically quibble with "exactly," but the point is unarguable: To successfully and quickly assemble a virtual enterprise, whether across-companies, as in the grand vision of agile manufacturing, or across departments within a company, the players' capabilities have to be known (well-estimated) and predictable -- they won't go unstable in a new enterprise. Measuring a company or a process in the dimensions of time, quality, and capability, with adequate and appropriate accuracy and precision, is in part a statistical problem.

The other precondition cited by Morton (1994) is that these new dimensional measurements be clearly communicated. Achieving clear communication will require standards for communicating information that goes far beyond part geometry, for example, to include process time, capability, and quality, as just indicated. He states, "interoperability will, in the end, matter more than pure performance, and assuring that systems in different companies work together will definitely require standards." This points to an already-existing NIST role in agile manufacturing and Morton cites STEP (the developing standard for the exchange of product data) in this regard. The role of statistics in formulating how to communicate estimates, standard errors, variance components, degrees of freedom, and the like, pertaining to a process's characterization (quality), needs to be considered.
The two fundamental problems in agile manufacturing are thus (1) determining what information should be developed and provided and (2) determining how that information should be communicated. Because much information is data-based, statistics is inevitably involved. The following sections discuss various aspects of this involvement.

\section{MANUFACTURING PROCESS MODELING}

There are two basic ways to make process predictions. One is to have data bases of the results of exercising various processes under various conditions. These could be searched to compare and select from alternatives for a given process. As an example, one of the Year 2006 agile manufacturing scenarios described in Nagel and Dove (1991) features the Factory America Network, which "provide(s) elaborately cross-indexed information about manufacturing capabilities, materials handling facilities, software development, engineering services of every kind, hardware and software product availability (together with price and performance data), marketing, and customer service expertise." Statistical issues in this context pertain to how information, such as the environmental conditions under which a process was operated, recognizable variance components, and the uncertainty in the estimates of process characteristics, should be conveyed.

The second way to make process predictions is through mathematical models. Predictions, in the agile, customized product world, are apt to be needed for conditions for which a process has not been run, or at least not run extensively enough to adequately 

characterize the process. At the development stage, there will be a need to make predictions for processes that may only exist on paper. In some cases, it may be possible to estimate process performance by interpolating between or extrapolating beyond neighboring process data (bearing in mind the general caveats mentioned above about the risks of drawing inferences from observational data), but there will also be a need to predict where no one has gone before. Further, to make predictions over combinations of processes, as illustrated by Fig. 1, and to try to optimize the combinations, a multiple data base search approach is apt to be unwieldy or infeasible. Mathematical models for processes, if they model the appropriate relationships and characteristics and are trustworthy, thus offer a second way to make process predictions for single processes and, if compatible, across combinations of processes. The Year 2006 scenarios in Nagel and Dove (1991) reflect the important role of mathematical modeling in agile manufacturing as follows: "Intensive use of computing power allows the properties of new products and the behaviors of new manufacturing processes to be predicted in advance."

There is an extensive amount of work going on today in the development and use of mathematical models to reduce design and evaluation time. "Virtual manufacturing," "virtual testing," and the "factory in a computer" are all expressions of this role for mathematical models. A commonly cited example is the Boeing 777 airplane, which was designed and analyzed in the computer so that the first unit built could also be the first unit flown. No mock-ups were required to assure that its parts would fit. At General Motors, the concept is "math-based vehicle development" (Cowger 1994 and McDonald 1993), referring to testing the engineering and manufacturing intent of a product via math models and computer simulation, rather than physical build and test. Processes that have been modeled pertain to applications that include sheet metal forming, aerodynamics, throughput analysis, heat flow, and structural analysis. An example cited by Cowger (1994) of the agility gains attributable to math modeling is that the time required to design an automobile hood has been reduced from 90 days to one day.

The type of model required to support agile manufacturing is one that predicts product performance characteristics as a function of design and process variables. In Fig. 1, the product characteristics of interest for the final product include things such as fit and strength, in the case of mechanical products; output voltage, current, and other electrical properties for electrical and electronic products; reliability indicators in either case, such as the stress (e.g., mechanical load or voltage) at which failure occurs and time-to-failure under various environmental conditions; and cost, in the traditional cost of materials and labor sense, but also environmental and maintenance costs over product lifetime. Time-toproduce is another important cost variable in agile manufacturing. Process variables include raw material characteristics, environmental conditions during production, and process settings, such as feeds and speeds for machining processes and temperatures and deposition rates for chemical processes. For a performance characteristic such as reliability, reliability models need to fold in use conditions and their effect on performance. In general, such integrated process-to-product-toperformance models are not available. The complexity and multidimensionality of the relationships are daunting. Nevertheless, models of pieces of the total process can be useful in making design decisions. Work towards integration, as discussed in the following paragraphs, is required, though, if these mathematical models are to be most 

effectively used in achieving rapid realization of customized products.

\section{Materials Processing Models}

A glance at current scientific and engineering literature shows the widespread effort in developing mathematical models of processes pertaining to manufacturing. Any attempt to categorize, summarize, and evaluate the status of such modeling in the context of agile manufacturing is well beyond the scope of this report. A recent paper, Szekely and Trapaga (1994) (abbreviated in the following paragraphs as ST), however, provides a very useful perspective on the mathematical modeling of materials processing operations, so I will summarize and comment on their view. Because materials properties are fundamental determinants of performance, this body of modeling is a major portion of potential process modeling. Readers familiar with the status of modeling in other areas, such as casting, machining, and assembling can evaluate the extent to which the materials processing perspective of Szekely and Trapaga applies in those areas.

In their review of materials modeling, ST indicate that "while major advances are being made in both the software and the hardware used in materials modeling work, and in the range of problems that are now being successfully tackled, most of the modeling work to date does not address the critical problems faced by the materials industry, namely the potential market for a new product, the trade-offs between cost and performance, manufacturability, and environmental impact." Making such tradeoffs and evaluations is the agile manufacturing challenge represented by Figure 1. ST's explanation for the lack of modeling work on these critical problems is that "very different groups of the (materials) community, with very different skills and attitudes, tend to study process on the one hand and product on the other."

ST's recommended future directions point to opportunities for statistics (though not called out by them explicitly). In their discussion of models, they distinguish two types: mechanistic models, which are based on fundamental physical and chemical relationships such as mass and energy conservation, and simulation (or empirical) models, which "seek to mimic a system mathematically, invoking experimental information, without paying particular attention to the process mechanisms involved." In passing, I would note that mechanistic models also only mimic a system mathematically, because, in general, they cannot capture all the physics and chemistry of a complex relationship and therefore have to make simplifying assumptions. They also may invoke experimental information to estimate certain parameters within the mechanistic model. Mechanistic modeling is generally the strict purview of physicists and chemists, but statistical aspects include the design and analysis of experiments to validate a model, estimate its parameters, and characterize the residual variation of the difference between model predictions and experimental data (because there will be some) and the corresponding statistical precision of the parameter estimates..

Empirical model building is in the realm of conventional statistics. Recent years have seen a great deal of growth, not all of it in the statistical literature, in the development of methods for fitting empirical models in complex, nonlinear, high-dimensional situations, so statistical tools and the computing resources to implement them are extensive (ST mention neural nets). The possibilities are considerably richer than the polynomial models that some might associate with statistical modeling. The traditional statistical issues of design, 

estimation, and uncertainty characterization still apply to these new methods, however. Also, it should be recognized that modeling need not be at one of two poles: mechanistic or empirical, since it's both possible and advisable for empirical modelers to pay attention to process mechanisms. For example, if physics indicates that a product characteristic depends on two processing parameters only through their ratio, then the empirical model should capture that relationship, not force-fit a polynomial in the separate parameters. Black-box modeling should become gray-box. There is a clear need and an opportunity to combine subject-matter and statistical expertise in the development of useful mathematical models. Will that opportunity be seized? Theorists will have to overcome a disdain of empirical modeling; statisticians will have to be willing to learn and more able to embody theoretical understanding than the blackbox approach requires. Truly collaborative relationships will have to be established.

ST, recognizing that mechanistic models are not apt to be able to bridge the gap between process and product, support a statistical view by stating that a "major advance could be made by the effective blending of mathematical (meaning mechanistic) modeling and empirical components." For example (my example), a mechanistic model might predict physical characteristics of a fabricated part, as a function of dominant process parameters. Predicting the (statistical) distribution of cycles to failure, though, as a function of these part characteristics, might require a designed experiment and subsequent empirical fit. Combining the models provides a means of predicting reliability as a function of process parameters.

ST also bring out the need to keep in mind the objective of model-building. Research objectives lead to deeper models of phenomena and increasing precision. Production problem-solving (and agile design decision-making) may need only a quick, approximate model that addresses major parts of the production process, rather than one micro-phenomenon within it. ST's concluding comment is that progress on issues pertaining to integration of process and product models "may provide a much greater impetus for new product and process development than the refinement of the micromodels that seems to be the major objective of most current research."

Where Szekely and Trapaga provide a glimpse of the statistical role in the development of process-to-product-toperformance modeling in the materials sciences, that role is the centerpiece of a recent workshop, reported by Karr (1994). The workshop, alliteratively sponsored by NISS (the National Institute of Statistical Sciences) and NIST, defined the problem by stating that the key needs for materials science, as an enabler of industrial competitiveness, "are to design components with desired performance, fabricated from materials with desired properties, and the processes to produce these components and materials via control of microstructure" (emphasis in original). Further, " $(t) h e$ ultimate goals are to optimize materials properties and increase reliability of components and systems." To which, from the agility perspective, I would add that design and optimization must be rapid. Accomplishing all this, the workshop concluded, will require statistical methods and the close collaboration of materials scientists with statisticians because "modern materials science is embedded in a 'sea' of statistics" (but not drowning, I hope). The argument behind this image is that the complexity of materials structure means that "intrinsic variability can only be characterized statistically." Furthermore, "(k)ey experimental data are uncertain and 

incomplete. Relations among structure, properties, performance and processing, derived from a combination of experiment, analytical modeling and numerical modeling, require statistical characterizations." (This last sentence relates directly to the point made by ST about the need for blending of modeling approaches.) The workshop report (Karr 1994) elaborates on these themes and provides several examples.

The combined perspectives of ST and Karr (1994) clearly identify the problems that exist and the approaches that need to be taken. Statistics should be an important contributor to solutions that can greatly reduce product realization time and enhance quality. The extent to which statisticians are already collaborating with materials scientists in developing the models needed by industry, and the prospects for healthy growth in those collaborations, are questions I cannot evaluate. Perhaps a follow-up query of workshop participants should take place. Statisticians should take the initiative to find out about materials science work being conducted at their institutions and look for opportunities to participate. The workshop report (Karr 1994) would be a good letter of introduction. Similar comments apply to other areas of manufacturing-process model development. Product performance depends on properties of its materials and the geometric shape in which it is rendered, so the integration of materials and forming and shaping models is apt to be required in order to predict product performance from process characteristics.

\section{Semiconductor Processing Models}

Blakey and Zirkle (1994) provide an industrial perspective on semiconductor modeling. They describe a conceptual sequence of models in the following order: equipment-process-device-circuit. That is, output from a process model, say, is (potentially) input to a device model. In their view, equipment modeling is in its early stages and the device-to-circuit link is often neglected. Integration of simulation tools has progressed to the point that "interfaces between most major tools are widely available ... and there is some automatic scheduling of multiple runs for optimization and statistical design," but they anticipate continued improvement in this area through standardization, natural language interfaces, and expert systems.

Blakey and Zirkle (1994) cite the potential benefits of simulation -- reduced physical testing time and costs -- and current difficulties in achieving those benefits. These include "unsophisticated" use, "inappropriate concentrations" of use (by specialists only), unrealistic expectations, and difficulties in measuring the benefits of using simulation tools. As an example of unsophisticated use they describe the practice of adjusting input parameters in order to make simulation output match experimental data, a process sometimes known as "tuning." When the tuned model is used for subsequent "what-if" studies, "the naive adjustment of an inappropriate subset of parameters can, and often does, lead to dangerously misleading results." As a technical concern related to statistical issues, they also note that since semiconductor processing is quite complex, often involving more than 100 steps, "(w)hen simulating an entire process the errors and uncertainties in the simulation compound at each step. It is consequently not yet possible to obtain accurate predictions of final structures by simulating a state-of-the-art process from start to finish."

NIST researchers Bennett and Lowney (1994) explore the field of semiconductor device simulation at considerable depth. 

Their perspective on empirical-mechanistic modeling questions is that "Conventional procedures for determining model parameters ... rely very much upon empirical relations, and give acceptable results for transistors with dimensions greater than about a micrometer. Such empirical procedures may not give reliable results for smaller transistors and they most likely will not be adequate for future devices that have features sizes less than about $0.2 \mathrm{~mm}$." In that situation, "one also needs device physics, based on first principles, to understand problems that arise in making reliable devices and to develop strategies to overcome design limits." The authors go on to develop "improved device physics (IDP)" models and show an example of situations in which IDP models provide considerably more accurate predictions of transistor gains than conventional (empirical) device models.

The semiconductor field has also seen the integration of simulation models with experimental design and analysis software to facilitate the use of simulation in evaluating alternate device designs. Wong et al. (1992) describe a Simulation Experiment Workbench that includes models relating device (e.g., resistor, transistor) structure to electrical behavior and experimental design and analysis packages for designing, running, and analyzing the results of experiments in which the device structure parameters are varied. The authors note a need to develop similar tools for process design.

\section{Discrete Parts Manufacturing Process Modeling}

In a NIST survey of methodologies of representing manufacturing process capabilities, Algeo (1994) focuses on information models (models for informa- tion flow among manufacturing functions), but also addresses mathematical models of processes. This survey provides a helpful entry into the literature pertaining to process modeling. One reference, Konig and Knop (1992), addresses the mechanistic vs. empirical modeling question in the context of grinding processes. They note the advantages of mechanistic modeling in terms of breadth of applicability and theoretical soundness, but cite the difficulty of modeling all the complex thermomechanical, grain-level, fundamentalphysics relationships in grinding, and in taking measurements that provide estimates of the coefficients in these relationships. Alternatively, at least for industrial production planning, they find empirical modeling to be satisfactory and illustrate the use of sums of exponentials to model product characteristics as a function of grinding process parameters.

Algeo (1994), in contrasting the state of industrial practice with state-of-the-art methodology, notes that "in production environments, representations of manufacturing process capabilities appear to be gradually migrating from printed media to electronic media. In many companies, handbooks are still the reference of choice " Further, at this early stage, there is a multiplicity of ways of representing process capabilities, so, in line with Morton (1994), she recommends developing a standard framework, terminology, and process taxonomy to facilitate the communication of process capability information.

PROCESS MODELING: STATISTICAL CONSIDERATIONS

In this section I will elaborate on some of the issues raised in the previous section. As 

a vehicle for considering these issues, consider the following model for the process-to-product-to-performance situation. Let $\underline{w}$ denote the controllable process parameters, such as speeds and feeds of a milling process. These parameters influence product characteristics, $\underline{x}$, such as dimensional deviations from target values, but they don't necessarily determine these characteristics because other uncontrolled or uncontrollable influences combine with $\underline{w}$ to determine $\underline{x}$. Conceptually, this relationship can be expressed as: $\underline{x}=\mathrm{g}(\underline{w}$, $\underline{e}_{x}$ ), where $\underline{e}_{x}$ represents all the extraneous influences. Similarly, $\underline{x}$ influences product performance $\underline{y}$, along with other influences such as the use environment, so $y=h\left(\underline{x}, \underline{e}_{y}\right)$. More generally, it might be the case that some of the process parameters and process "noise factors" also influence $\underline{y}$ in ways not manifested in $\underline{x}$, so $\underline{y}=\mathrm{h}\left(\underline{x}, \underline{w}^{\prime}, \underline{e}_{y}, \underline{e}_{x}\right)$, where the primes denote subsets of the original vectors.

A simple context in which to envision this sort of relationship is dimensional stack-up of mechanical parts. Processing variables, $\underline{w}$, influence part dimensions, $\underline{x}$. The product characteristic of interest would be $y$ $=\mathrm{S} x_{i}$, or perhaps some more complicated function of the part dimensions. Of ultimate interest might be some measure of process capability, such as $\operatorname{Prob}(\mathrm{L}<y<\mathrm{U})$, where $\mathrm{L}$ and $\mathrm{U}$ are specification limits, but this requires probabilistic considerations, not yet introduced.

In the general situation, approximating these relationships via mathematical models provides a means of making process design decisions, such as the choice of process parameter nominal settings and tolerances. A process model can be expressed as $\underline{x}^{*}=$ $\mathrm{g}^{*}\left(\underline{w}^{\prime}, \underline{e}_{x}^{\prime}\right)$, the primes denoting the possibility that only subsets of the process parameters and additional influences may be contained in the model, the asterisks denoting that the model and resulting calculated product characteristic are approximations to the actual relationship and product characteristic. The actual product characteristic can be expressed as $\underline{x}$ $=\mathrm{g}^{*}\left(\underline{w}^{\prime}, \underline{e}_{x}^{\prime}\right)+\underline{e}_{x}^{\prime \prime}$, where $\underline{e}_{x}^{\prime \prime}$ is the difference between prediction and actual and contains influences not captured in $\mathrm{g}^{*}$ and lack of fit of $g^{*}$ to $g$, in a general sense. In a production run, these influences may vary in such a way that it makes sense to treat $\underline{e}_{x}^{\prime \prime}$ as random and thus, to make predictions, one would need to estimate its distribution. In other contexts, bounds on $e_{x}$ " over some domain of $\mathrm{g} *$ may be appropriate.

This depiction of the process-to-product-toperformance chain needs to be expanded as in Fig. 1. The process to convert raw materials to a product is actually the combination of multiple processes, each of which may be the subject of a mathematical model. Figure 2 shows a serial linkage of processes and illustrates how the output of one process, along with process-specific process and environmental variables, are input to a subsequent process, all culminating in a product with performance characteristics, y. Thus, models for processes need to be compatible for a similar linkage. Research-oriented model development is aimed at improving a single $\mathrm{g}_{\mathrm{i}}{ }^{*}$ as an approximation to $\mathrm{g}_{\mathrm{i}}$, generally by bringing additional variables and relationships into the model. The point of view of ST, discussed above, is that for the sake of improving production capabilities, there should also be research done that is aimed at assuring that some sort of model, even empirical, is in place for all the $\mathrm{k}$ models required to predict product performance. Having a very sophisticated, deep mechanistic model, $\mathrm{g}^{*}$, for a particular process, doesn't help solve production problems if there are glaring gaps in the chain of models required to predict product performance. 



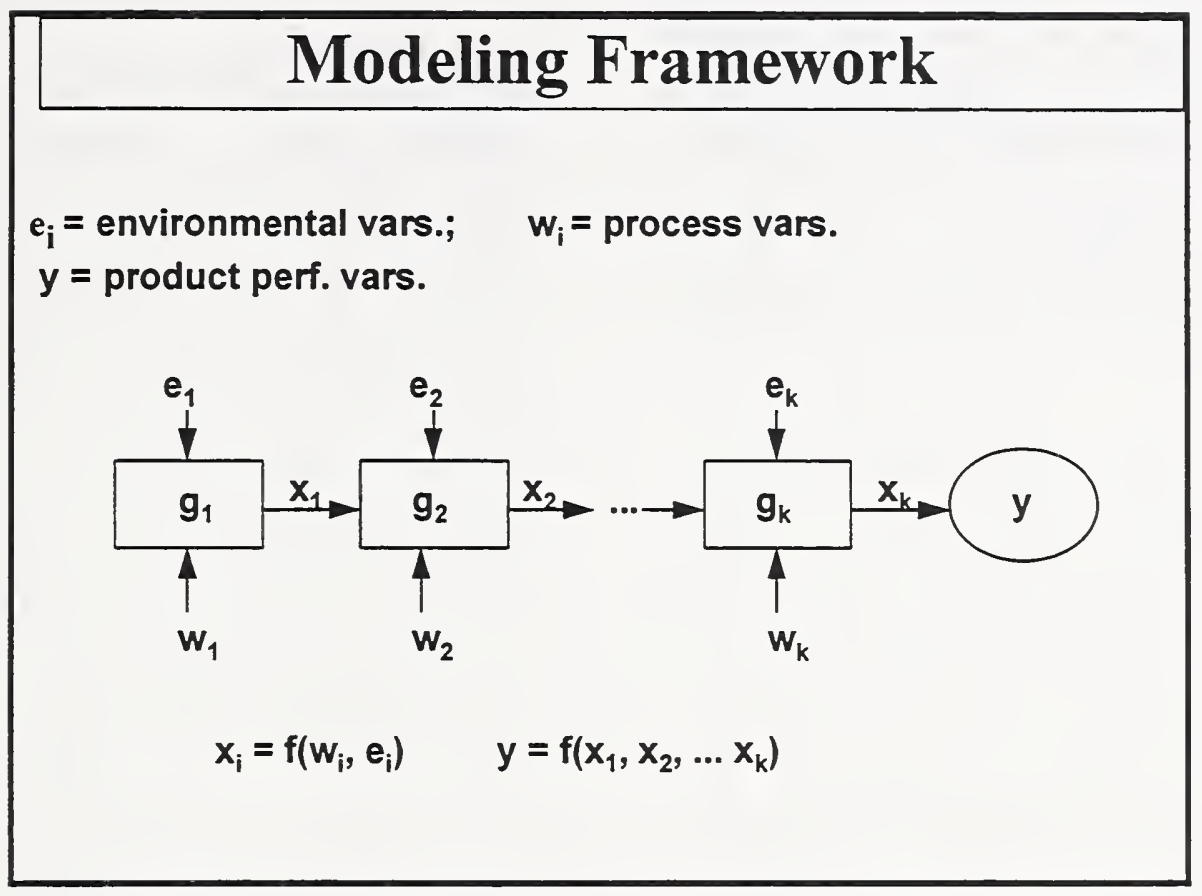

Figure 2. Modeling Framework

Model Validation

One value of a model is that it can provide predictions for process configurations, designs, settings, or environments not previously observed, but no matter the theoretical soundness of a mechanistic model, there is still generally a need to check its predictions against data from an experiment or the actual process. This can be a contentious issue. For example, a Washington Post article (October 14, 1994) described a controversy over the credibility of predictions of improved Patriot antiballistic missile reliability based on simulations (the term is here being used in the general sense, not ST's categorization of an empirical model), in the absence of field tests against actual Scud missiles. (In a reverse twist on this issue, I recently heard about an experimental program, well-run by all accounts, that had its funding canceled because its experimental results did not match the predictions of a state-of-the-art computer model.) I asked the provider of fluid dynamic codes what provided assurance that applying a code in a new situation would yield trustworthy results. The answer was, "Well, I try to get a little data." Deciding how much data and at what conditions, i.e., settings of the model inputs, $\underline{w}^{\prime}$ and $\underline{e}^{\prime}$, is a difficult and important, and in part a statistical, issue. The model may be designed to be used over an extensive multidimensional domain. Testing, for economic reasons, can only be done at a small number of points in that space. How to choose? Consider the problem of estimating Patriot reliability over a wide range of encounter scenarios. Subjectmatter expertise and theory can help narrow the choice of test conditions, but where tests have not been done, one often has to 

rely on face validity -- the simulation results look reasonable.

The need to validate computer predictions is well-recognized by the modeling communities. Thus, various groups have assembled benchmark sets of data against which modelers can test their models. For example, a NATO aerospace group recently published 39 test cases pertaining to air flow around aircraft and missile configurations (AGARD 1994). In the semiconductor area, Meyyappan (1994) notes that "(T)here is a critical need for benchmark experiments in the field of semiconductor processing," and goes on to offer this perspective on mechanistic and empirical models:

When quantitatively accurate predictions are required, the need for validation and benchmark experiments becomes essential. A case in point is the role of models in real-time process control. At present, development of process control strategies is based on data from many well-designed experiments [5]. The data is (sic) fitted into empirical models using Box response surface [9] or Taguchi orthogonal arrays [10]. This approach is complex, time-consuming and expensive. Computational modeling is ideally suited to replace the above procedure.

So, here is a case in which mechanistic modeling is suggested as a cost-effective alternative to empirical modeling. Experimental models that are rich can require extensive experimentation, data collection, and analysis to develop. Mechanistic models can be intrinsically rich. The amount of experimentation, data, and analysis required to validate that richness should be less than the amount required to construct a comparably rich empirical model. These are issues that need to be examined at some depth. In some circles there is a euphoric sense that computer models can virtually eliminate the need for physical experimentation.

A problem that can occur in model validation efforts is that some key model inputs may not be measurable in an experimental or field situation. This can lead to tuning exercises, trial and error attempts to plug in physically reasonable values to improve the match of model and data. The interplay of tuning and validation is another issue that deserves some thought. Incidentally, a designed experiment approach to multi-parameter tuning may make the search more efficient.

\section{Computer Experiments}

One way to focus model validation tests is to first identify what model inputs are the dominant influences on model output. Then, the validation experiment could focus on whether those influences are properly characterized by the model. In a complex model, such as one incorporating finite element analysis, it may not be at all clear what the dominant inputs are. Designed experiments are one way to attempt to identify dominant inputs. These "computer experiments," so called because they are experiments in which the experimental apparatus is a computer code, can also be used to obtain faster-running, more "agile," models that might be required, in the context of Fig. 1, to help a decision-maker choose among alternative processes or to select desirable process settings. Another need for faster-running models is in a Monte Carlo analysis, as described in a subsequent section on virtual prediction. 

The design and analysis of computer experiments has received a fair amount of attention in recent years (see, e.g., Morris et al. 1993, Welch et al. 1992, and Sacks et al. 1989 and references therein). As mathematical models become increasingly important in supporting agile manufacturing, computer experiments on those models, and the communication of their results to people involved in selecting or optimizing processes, will become more important in the manufacturing arena. The approaches taken in the referenced articles are generally much different from those used in the design and analysis of physical experiments, so the differences are worth examining. Some particular contrasts:

- In a computer experiment, all the variables that might influence the result, namely the model inputs and internal parameters, are known and controlled; they have to be given values in order to run the model. In a physical experiment, there may be a comparatively small number of known and controlled potentially influencing variables and a large number that are uncontrolled. Thus, repeating a computer experiment yields identical results (excluding the case in which the computer calculation draws on random numbers) while repeating a physical experiment does not (at some level of resolution).

- In a computer experiment, because there are conventionally a large number of explanatory variables (model inputs), all of which are apparent and controllable, there is a tendency to include a large number of variables in the design, in the sense that their values are deliberately varied over the set of runs. In a physical experiment, there is a tendency to focus first on variables thought to be important and build a design primarily on them. Variables not included in the design are either overlooked, deliberately held constant, or allowed or encouraged, via randomization, to vary freely (but their values would be unknown and thus could not be part of any modelbuilding, except in the sense of characterizing residual variation). In a computer experiment, in order to randomize over thought-to-be extraneous variables, one would have to assume probability distributions for them, which might be difficult to justify. In a physical experiment, "nature" distributes these variables (to the extent allowed by the experiment protocol).

- Even in the case of a similar number of variables to be included in the design, experimental designs are very different for computer and physical experiments. Computer experimenters tend to use very highly fractionated multi-level designs. For example, a Latin hypercube design (see, e.g., McKay et al. 1979) for 32 runs in 10 variables is a $32^{-9}$ fraction of a $32^{10}$ factorial. The design for a physical experiment in this case is apt to have only two or three levels of each variable, say a $2^{10-5}$ fractional factorial, or perhaps a L27 design for three-level factors, augmented with a few other points, or an orthogonal main effects design for a mixed number of levels. Part of the appeal of the designs with more levels, less orthogonality, is that when extreme effect sparsity permits projection on to a small number of input variables, the multi-level designs provide detailed information about the nature of the relationship. Similar projections for two- or three-level factorials result in a lot of redundancy. (In a physical experiment, this redundancy would at least provide degrees of freedom for 

estimating the error variance -- not an objective in a computer experiment.)

- Computer and physical experiments have different design ancestries. Early computer experiments were, in essence, a means of numerical integration: Given input-variable probability distributions, the objective was to convolute these to approximate the probability distribution of the output variables. Thus, by using a Monte Carlo approximation to numerical integration, random, or constrained random (especially Latin hypercube), selection of inputs constituted the "design" of the computer experiment. These pseudo-random results could subsequently be analyzed, much as in the case of observational data, to try to identify dominant influential variables and to fit simplified models. Physical experiments have not had the distribution-approximation objective, the nearest analogy being to draw a random sample from a defined population in order to estimate the distribution of some characteristic of individuals in the population. When variable screening, or simplified-model fitting became the objective, computer experimenters have either continued to use Latin hypercube designs (e.g., Welch et al. 1992) or have tended to use a number of levels somewhat intermediate between the extremes just discussed, selecting designs from the very large number of possible combinations, e.g., $5^{10}$, by various optimality criteria (Morris 1994).

- The fitting functions tend to differ. The primary approach of computer experimenters is to represent the computer model as a realization of a stochastic process and use smoothing methods, such as kriging, to obtain a simplified model. Such fits have the desirable feature that the fitting function passes through the observed results, which, of course, are known exactly. Physical experiments could be similarly fitted, but are conventionally fitted by polynomial models, perhaps using transformed variables, or by theorybased functions. These need only pass close to the observed results (within experimental error, which is not of interest in computer experiments). Fitting stochastic process models can be quite computing-intensive (as can the selection of a design). Fitting regression models can be quite analysis-intensive, as different functional forms, transformations, and other tricks of the trade are tried.

\section{Comment}

I tend to favor approaching computer experiments essentially as I would approach physical experiments (Easterling 1989) because the fact that the experimental apparatus is a computer model doesn't seem to me to warrant a whole change of perspective. That is, if I had a table of results from a lab experiment in temperature, pressure, and humidity, I wouldn't interpret it as a realization of a random process and therefore fit a spatial covariance function (treating temperature, pressure, and humidity as spatial dimensions), and I doubt that many computer experimenters would either, so I don't see how being told that the table was computer-generated would motivate a dramatic change of approach. If told the objective was to smooth a function through the tabled values, then, as a mechanical means of doing so, I'd choose some multidimensional smoother, recognizing that (at least for me) this is a somewhat arbitrary choice among the myriad of possibilities. I might use cross-validation to provide some guidance. If told the objective was to find 

dominant variables, I'd take a more conventional regression approach, for the sake of familiarity and interpretability. Standard errors are a problem in this case, but I'm not sure the standard errors of prediction provided by a kriging analysis, e.g., are really more interpretable.

The different fitting approaches can be contrasted as follows. In general, a model output, $x$, is treated as a realization of

$x=\mathrm{g}(\underline{w})+\mathrm{e}(\underline{w})$,

with $\mathrm{g}\left({ }^{\prime}\right)$ representing signal, $\mathrm{e}\left({ }^{\prime}\right)$ noise. Conventional regression modeling tries to capture all the structure in $\mathrm{g}$, leaving e to look like pure noise (independent, identically distributed). The random process approach tries to capture all the structure in the covariance function for $e$, often letting $g$ be a constant. For a set of deterministic computer model runs, it's hard to claim either is right (particularly in the calculation of standard errors); either may be useful for certain purposes.

For the design of a computer experiment, I would use factorial-based designs, modified to overcome the projection shortcomings mentioned above. Thus, in the example, rather than a $2^{10-5}$ design, say at corners of the $( \pm 1)$ cube, I might run a $2^{10-6}$ at \pm 1 plus a $2^{10-6}$ at corners of a $\pm a$ cube, with $a$ equal to $1 / 3$, say, or maybe $1 / 2$. Or, I might run an orthogonal array of 10 four-level factors in 32 runs. Then, if the model is dominated by only two variables, there are 16 points on which to characterize this relationship. These suggestions pertain, though, to a black box approach. On a real problem, I would want to select levels and design the experiment based on subjectmatter insights, but still with a factorial orientation. I would also advocate a sequential strategy in exploring these complex, high-dimensional relationships in order to test and improve predictions.

\section{Process Capability Prediction}

The product and process designer, facing design options as in Fig. 1, needs information pertaining to the probability that a process will yield output that will meet design requirements. This characteristic of a process is generally referred to as process capability and various indices have been created to try to summarize a process's capability. In this report, though, capability refers more broadly to any comparison of a process output distribution to requirements, such as specification limits, for that output. Prediction is the term used because the context is the prediction of a process to be used in the future, possibly in a different configuration than in the past, or of a process that does not yet exist. Three situations will be considered:

- The process exists and has been exercised or is available for experimentation

- A prototype or laboratory version of the process is available for experimentation

A mathematical model of the process is available.

\section{Process Capability Prediction Based on Physical Experimentation}

Historical data from a process could be summarized as follows: At process setting, $\underline{w}_{i}^{\prime}$, product characteristic $x$ has a distribution with (estimated) mean, $\mathrm{m}_{\mathrm{i}}$, and standard deviation, $\mathrm{s}_{i}$. (In some cases, it would also be appropriate to include variance components, such as variability among machines, operators, or set-ups.) A process capable of being operated at various settings could be summarized by such statements at different settings. A robust process would have essentially the 

same output distribution over a wide range of process settings. The variability represented by these distributions results from the variability of influences on the process not controlled by $\underline{w}_{i}^{\prime}$, such as variability in incoming material and the environment in which the process is being operated. If this process is being reconfigured into a new manufacturing system, these influences may change, resulting in different distributions. This possibility needs to be considered before past experience is accepted as a prediction of future performance. Enough information needs to be provided to make an engineering judgment that previous experience is applicable, or it may be necessary to conduct test runs under the altered conditions. Demonstrated process robustness -- takes a licking and keeps on ticking -- is a boon to reconfigurability.

Similar concerns pertain to using lab or prototype test assessments of variability as predictions of actual use of the process. The "cause system" influencing variability in the lab may be much different from that in the field, so theory, or an empirical bridge, is required to make the connection.

Historical data may not lend themselves to ready summarization, as described, so it may be necessary to run an experiment on the actual or prototype process. To do so, the design issues discussed above for computer experiments need to be addressed. In particular, of all the possible influences on the process, denoted by ( $\underline{w}$, e), some will be controlled and varied according to the experimental design, some will be held constant, and some will be allowed to vary freely. The same issues have to be addressed if the objective of the experiment is to provide a basis for fitting an empirical model that can be used to mathematically represent the process. For the sake of providing information on reconfigurability, the span of conditions over which to experiment is apt to be wider than would be done for a dedicated process because of the need to use a process in different circumstances and in different combinations. It behooves the "owner" of a process who wants to play in the reconfigurability arena to characterize that process as broadly as possible and make the information known to enterprise management (prospective suitors).

Assessing process capability requires comparing an estimated output distribution to specification limits for that output. However, when a process is operated, it is generally operated under conditions that require it to meet certain tolerances. In fact, a tolerance could be, in essence, a process setting in $\underline{w}^{\prime}$. For example, a machine tool is operated to produce parts with certain dimensions falling within specified tolerances. The machinist will design a sequence of rough and finish cuts to achieve this quality. Thus, the output distribution will (generally) fall within those tolerances and it may not be clear whether the basic process has this capability, whether herculean efforts are required, or whether acceptable product has been achieved by scrapping and reworking parts produced from what is really an incapable process. Cost, processing time, and first-pass acceptance data may reveal the difference between a capable process and a highly inspected and screened incapable one. It would be better, however, to have pre-screening process output distributions to use in evaluating a process against requirements that are possibly different from the ones in force at the time.

\section{Process Capability Prediction Based on Mathematical Models}

If a math model, $\mathrm{g}^{*}\left(\underline{w}^{\prime}, \underline{e}^{\prime}\right)$, exists, then process capability can be predicted by propagating estimated, or assumed 

distributions of the process arguments through that model. Complex, longrunning models may not be feasible for such Monte Carlo exercises, so simpler models, obtained either by simplifying the mechanistic model or by developing empirical models from computer experiments, may be required. Statistical problems arising in this situation are the approach to model-fitting, already discussed, and the estimation of distributions of the process arguments.

To summarize the issues in process prediction in a specific situation, consider the following simple relationships:

$x=\mathrm{a}+\mathrm{b} w+e_{x}$

$y=\mathrm{g}+\mathrm{d} x+e_{y}$

That is, suppose theory indicates that product characteristic $x$ is linearly related to process variable $w$, but with some residual error, $e_{x}$. Similarly, performance characteristic $y$ is linearly related to $x$, with residual error $e_{y}$. Further, suppose that the residual errors are modeled as random variables that will vary in production with mean zero, and standard deviations, $\mathrm{s}_{x}$ and $s_{y}$. Also, in a production environment, $w$ will vary according to some distribution, say with mean $\mathrm{m}_{w}$ and standard deviation $s_{w}$. (For example, the process may specify a particular temperature, but the imperfection of temperature control results in variable actual temperature.) Now, suppose that all of these (statistical model) parameters have to be estimated. From these estimates, the resulting distribution of $y$ can be estimated to have a mean of

$M_{y}=g+a d+b d m_{w}$

and a variance of

$s_{y}^{2}=b^{2} d^{2} s_{w}^{2}+d^{2} s_{e}^{2}+s y^{2}$, where English letters represent estimates of their Greek counterparts. There are two major statistical problems to address in this situation: 1. How precise are these two estimates? Can their statistical uncertainty be characterized by standard errors or confidence limits? (We need some indication of statistical uncertainty in order to be able to compare alternative processes or just to know how well process capability is being predicted.) 2. How should the experiments or data collection efforts from which these estimates are to be obtained be sized and designed in order to achieve a desired degree of precision? Even for these simple linear relationships, addressing these questions is not straightforward. Initial steps are reported in Easterling (1995). Addressing these questions for multidimensional, complex relationships is going to be a formidable challenge.

Any prediction is limited, of course, by the quality of the models and the data on which it is based. Thus, until the point at which the producer is very sure of the process and product models, the next step would be to build and test some (small) number of prototypes in order to be sure that things can operate as predicted. Determining a set of conditions under which to build and test prototypes and determining what performance constitutes adequate agreement with predictions is another area of potential statistical involvement. The issues are analogous to those in deciding what physical tests are required to validate a single model.

There is a similar situation in reliability prediction: Given component test data and a system reliability model, the analysis objective is to predict system reliability and evaluate the statistical uncertainty of that prediction. In the agile manufacturing context, we will have process data and a manufacturing system model that links these processes to product performance. In 

the reliability situation, a system designer may have choices among components and other design features such as system architecture, so the predictions would be used in making design decisions. As in the process capability situation, reliability predictions are conditioned on assumptions that the system operates as modeled and the component data are representative of in-use functioning. Some limited number of system tests are necessary for checking these assumptions. Further, the reverse problem of deciding on a suite of component test plans that will yield a system reliability prediction with predetermined precision has also been addressed (Easterling, et al., 1991). In reliability, though, the type of data, e.g., binary pass/fail data, and system model considered, typically sums and products of component failure probabilities, are apt to be simpler than the process characterization data and process and product models envisioned here, so extending the reliability analogy to the agile manufacturing context will require considerable effort. The approach will have to be to simplify the models and focus on the dominant contributors of performance.

\section{Tolerance Allocation}

In passing, I would note that the Fig. 1 schematic can also apply to the problem of tolerance allocation. Suppose that final product characteristics are required to fall within some tolerance intervals about target values for those characteristics. Achieving this will require the specification of tolerances for various part characteristics, say, for the case of mechanical assemblies. The different parts could be built to different tolerances, at different costs. The problem is to decide how to allocate the tolerances, assuring that the final product requirements will be met, at minimum cost. Solution requires a model relating part dimensions to final product characteristics, reasonable cost estimates, and reasonable estimates of the distributions of parts characteristics for each alternative tolerance. A recent reference is Zhang and Wang (1993). Statistical issues that arise are the same as in the above discussion of predicting the capability of a production process created by the linkage of several individual processes.

\section{AGILE MANUFACTURING AND QUALITY}

In the agile manufacturing world envisioned in Nagel and Dove (1991), quality is assumed. You're not even in the game if you cannot make high-quality products, quickly and economically, and if you are not attentive to customer current and potential future needs, from whence will come the market for new, customized product. Low-volume production and the need for rapid, economical product realization means that scrap, rework, and product inspection and testing must all be minimized. Production processes will have to be not only capable, predictable, and continuously improved as customer needs evolve, but they must also be reconfigurable and robust to reconfiguration. Modern quality assurance has evolved from inspection and testing to an emphasis on process understanding, design, monitoring, and control, but the needs of agile manufacturing ought to accelerate that evolution.

In a broader sense of quality, agile manufacturing, in its model of crosscorporate cooperation in virtual enterprises, even among companies that might be competing in other arenas (as in automobile 

joint ventures), reflects Deming's views on the quality and productivity advantages of cooperation over competition. It should be recognized, though, that reconfiguration can be anti-quality if it results in the introduction of extraneous sources of variation. For agility to work, echoing the remarks of Morton (1994) cited earlier, process interfaces will have to be worked very carefully and processes will have to be quite stable and predictable to avoid surprises in production. On the social side, quickly establishing trust as configurations among companies, or organizations within companies, change may also be an obstacle to successful agile manufacturing.

Achieving quality in agile manufacturing begins with the design of both the product and the manufacturing process. Process monitoring and control then help assure that the design intent is achieved. Ideally, there would be no need for final-product inspection and certification, but in practice, some product testing will often be needed. Mathematical process modeling, as described in the previous section, will help achieve "agile quality assurance," by contributing to process design and control, but there are additional aspects, and corresponding statistical roles, that will be discussed in this section.

\section{Integrated Product and Process Design}

Integrated Product and Process Design (IPPD) is the term used to represent the concurrent design of a product and its production processes so as best to use existing manufacturing processes or to develop new processes in a timely manner that will be highly capable of producing the product. (Concurrent engineering is another term used interchangeably with IPPD, though some argue one is a subset of the other.) As an engineering practice, IPPD is approached by establishing product teams early in the design process that include manufacturing personnel. Thus, it is by forced early communication that production problems are prevented. It is my impression that industrial statisticians are not generally part of these integrated design teams -- they more often play the role of a specialist called in to help address specific problems -- but the opportunity to be well-immersed in a design project can enhance the contribution a statistician can make to the project when statistical approaches to problem-solving are required. A case in point is Sandia's A-PRIMED project, described in a subsequent section.

There is a need, though, to go beyond the avoidance of production problems via early communication and to try to optimize (or at least greatly improve) the product design and production processes. Designs generally begin at a point and then are improved one factor at a time as problems are encountered and resolved. Having all the players involved at the start can speed up this process and multiple engineering insights can greatly help in negotiating a high-dimensional design space. A more systematic exploration of the product and process "parameter space," however, can lead to solutions that might otherwise be missed. This is where the "factorial" perspective of a statistical team member can make a contribution (and it's a contribution that the specialist might never be called on to make). Experimentation that plays design features against alternative production processes (or process settings) can provide the basis for optimization. The genius of the Taguchi approach (see, e.g., Nair 1992 and Kacker, 1985) to robust design (in this case, a product design that is robust to production process noise) is that it calls for early experimentation that simultaneously addresses product and process designs. Technical issues pertaining to experimental design and data analysis can sometimes obscure the basic fact that experimenting 

with the right factors, over the right ranges, at the right time in the product design cycle can be the key to real quality and productivity breakthroughs.

\section{Process Control}

Real-time process control, by which process deviations from target can be sensed and translated into course corrections, is another means by which quality assurance can be provided in agile manufacturing. A considerable amount of engineering and statistical work is aimed at the development of process controllers. Statistical and engineering approaches often differ, but some recent work that blends them is Montgomery et al. (1994) and Vander Wiel et al. (1992).

An example of statistical modeling for the purpose of real-time process control is provided by a recent NIST project (Rudder et al. 1992). In a milling operation, temperature affects cutting accuracy and temperature can vary as a piece is milled. Quality could be improved if in-process temperature changes could be detected and translated into compensating modifications of the tool path (this assuming that process parameters, such as speed, feed rate, and coolant, have been determined that reduce temperature fluctuations to the extent possible, but that the remaining temperature effects still need to be compensated for). To this end, a vertical axis milling machine has been extensively instrumented, data collected, and empirical models developed.

\section{Process Change-Over}

Agile, customized production can call for frequent process change-overs, say from one recipe to another. Time and cost are saved if the new process can be targeted quickly, without a lot of tweaking and stabilizing. Statistical aspects of this problem pertain to the development of databased decision rules for accomplishing the change-over and these have recently been addressed by Faltin et al. (1994) at General Electric. Other work in this area is $\mathrm{Hu}$ (1994).

\section{Short-Run Process Control}

Traditional quality assurance requires a substantial amount of production to establish statistical control limits against which subsequent production is to be compared. Recent statistical work is aimed at modifying this approach for use with very limited amounts of data (Quesenberry 1991 and Crowder 1992). The ability to detect process shifts via product-specific, low-volume or short-run (lot size 1?) data, though, may be so limited as to be not worth the effort. Inspection against specification limits, not statistical control limits, may be all that can be done. Applying statistical process control to processes that are repeatedly used, in different configurations and for different products, perhaps, is more appropriate. Some adjustment for configuration differences may be required to make crossconfiguration data compatible.

\section{Final Product Testing}

Qualification or certification of product can inhibit agility (quote from industry colleague: "Measurement is killing us!," meaning the time and expense). Two approaches to reducing the measurement burden are (1) to reduce the amount of measurements and (2) to reduce the time required for necessary measurements. Reducing the number of measurements required, especially at the final product stage, can be accomplished by eliminating redundant or noninformative measure- 

ments; statistical methods can be used to achieve this dimension reduction. Better still, the elimination of the need to do final product tests via process understanding, control, and monitoring of process variables can greatly reduce the qualification component of the product realization cycle.

To reduce the time required to take measurements, methods such as onmachine inspection of mechanical parts (as opposed to moving a part from the machine on which it is produced to a special measurement station) are being developed. Because some machine biases may also be present in on-machine measurements, not all off-machine measurements may be eliminatable. Statisticians can help qualify on-machine measurements by the design and analysis of studies that compare onmachine measurement to off-machine measurements by standard methods, such as via coordinate measuring machines.

\section{Framework for Quality Assurance}

The mathematical framework presented above for relating process variables, $\underline{w}$, to product characteristics, $\underline{x}$, to product performance variables, $\mathcal{x}$, also provides a framework for quality assurance. Postproduction quality assurance focuses on $\mathcal{y}$. Each unit produced is measured for form, fit, and function to the maximum extent possible and acceptance is based on those measurements. Performance characteristics that can only be measured destructively, such as lifetime, or burst pressure, might be measured on a sampling basis. By this approach, which might be labeled traditional quality assurance, the burden of proof that the realized product meets requirements is provided by tests on the final product. While such testing maximizes the realism of a quality evaluation, it can be expensive and tardy in identifying process problems.
Alternatively, if the relationship between product characteristics, $\underline{x}$, and performance variables, $\underline{y}$, is well-understood, measurements of $\underline{x}$ can provide the basis for product acceptance. For example, deflection under some nondegrading load might be a good predictor of breaking strength, which could only be measured destructively, so measured deflection would be a surrogate for breaking strength and product acceptance could be based on meeting requirements in terms of deflection. Moving further upstream, if the relationship of deflection to process parameters, $\underline{w}$ and environmental parameters $\underline{e}$ is understood, then deflection can be controlled by controlling $\underline{w}$ and $\underline{e}$. The product and performance characteristics, $\underline{x}$ and $\underline{y}$ might never need to be measured, or at most be measured on a sampling basis.

Process monitoring and product testing, perhaps on a sampling basis, provide an ensemble of $\underline{w}, \underline{e}, \underline{x}$, and $\underline{y}$ data. It seems to me that there ought to be ways to use all of these data simultaneously, in ways other than just comparing them to their specifications, to provide assurance that processes and product are on target and to detect departures from target. For example, the $(\underline{x}, \underline{y})$ data could be used to check that the assumed relationship between them has not changed. That evidence should add quantifiable assurance to that provided by the separate comparison of $\underline{x}$ and $y$ to their requirements.

All of these relationships, of course, are what underlies design. In order to achieve product that meets customer requirements in terms of $y$ the product should have characteristics $\underline{x}$ that meet certain requirements (the designer says). Achieving this requires manufacturing processes that run at settings $\underline{w}$ under environmental conditions $\underline{e}$ that both fall within prescribed limits. The ability to set limits on $\underline{w}, \underline{e}$, and $\underline{x}$ is derived from the understanding of the relationships 

of these variables to $\mathcal{y}$. When that relationship is not well-understood, conservative margins are used to provide assurance that realized product will meet customer requirements. Compensations for measurement uncer-tainty introduce further conservatism. Improved understanding, reflected in improved mathematical models of the relationships, and improved measurement precision can lead to reduced margins and reduced costs. -- i.e., greater agility.

\section{THE AGILE MANUFACTURING RESEARCH AGENDA}

As a developing concept, agile manufacturing is the subject of ongoing research and development. Government funding for such research, that I am aware of, is coming from the Departments of Defense, Energy, and Commerce and the National Science Foundation. This section describes some of those programs, with emphasis on statistical aspects of that research. Of course, all research and development, government or privately funded, that is aimed at reducing product realization time also contributes to agile manufacturing. Numerous statistical opportunities exist in the development and testing of new manufacturing technologies and many government, academic, and industrial statisticians are involved in this research.

With respect to agile manufacturing, in brief, the Advanced Research Projects Agency (ARPA) of the Department of Defense funds the Agility Forum, in part to help set the research agenda in agility. ARPA then funds particular research programs. The Department of Energy is sponsoring agile manufacturing $R \& D$ at its national laboratories and a lab/industry program called TEAM (Technologies
Enabling Agile Manufacturing). The National Science Foundation sponsors agile manufacturing research at three AMRIs (Agile Manufacturing Research Institutes). These are located at the University of Texas at Arlington, Rensselaer Polytechnic Institute, and the University of Illinois and focused on three manufacturing sectors: electronics, aerospace, and machine tools, respectively. NIST, in addition to supporting the Agility Forum and TEAM through membership on various panels, has internal programs pertaining to the infrastructure of agile manufacturing and also funds some industry programs through the Advanced Technology Program. This section briefly describes these programs with focus on their statistical aspects.

\section{ARPA}

The ARPA request for proposals for its Agile Manufacturing Initiative, issued as a Broad Area Announcement (BAA) in the summer of 1994, begins with a sweeping description of agility:

"Agility in manufacturing is viewed as the ability to thrive in an environment of continuous and often unanticipated change through an enterprise geared toward 'reconfigurable everything.' Agility addresses ... business practices; the culture of management and employees; financial control and operations; relationships of the customer, assembler, and supplier; manufacturing process integration with design, information systems to support decision making, (and) information systems for empowering workers; accounting systems to reflect 

operations; and education and training. This initiative includes the 'lean manufacturing' emphasis on the streamlined, efficient use of resources and the minimization of waste, and the best commercial quality management practices of customer focus, an empowered and knowledge-able workforce, team-work, communication and continu-ous improvement. It also includes integrated product/ process development and flexible manufacturing capabilities; requires flexible management structures with commitment to societal and environmental concerns; and requires a networked infrastructure capable of supporting 'virtual corporations' and other agile organizations that can respond to rapidly changing market demands."

This description has a clear emphasis on the infrastructural aspects of agility -- the supporting and connective tissue of a manufacturing enterprise. The primary technical aspects of this description are "manufacturing process integration with design," and "integrated product/process development," which are about the same thing. Pilot projects in these areas are invited and the Initiative will also fund the development of technologies that enable agile manufacturing. The scope of enabling technologies is virtually unlimited, but at this time the ARPA focus is on "Enterprise Communications, Command, Control, and Intelligence" (the military perspective is clear) and at this point becomes statistically interesting.
The interesting analogy is to think of virtual enterprise management as battle management. Sensors throughout the enterprise provide data that need to be converted into information that will determine subsequent actions. The enterprise management system, in the terms of the BAA, should provide a "current state estimate ... (that is) ... based on autonomous collection of data ... and reduction of that data (taking the uncertainty of the data into account) to the parameters used in the state estimate." Further, the system should provide a future state forecast for which "(c)are must be taken to deal with propagation of the uncertainty in the state estimate." Subsequent actions can then be planned.

I hope there will be statisticians involved in developing such systems (there are lots of uncertainty propagators about who are not very statistical). Conceptually, it's very intriguing. This is (statistical) process monitoring and control at the enterprise level, rather than the production process level. There are design issues to address:

- What sites in the enterprise should be "instrumented" and what should those instruments measure?, data analysis/ condensation issues:

- What functions of the data estimate (describe) current state?, and modeling/ forecasting issues:

- What functions of current (and probably recent) state estimates predict what's going to happen next?

I infer from the ARPA material that battle management systems have addressed such issues; it would be interesting to know more about how these common statistical issues in a very nontraditional setting have been addressed. 

TEAM (Technologies Enabling Agile Manufacturing)

The basic goal of the TEAM project (TEAM 1994) is to make available, to industry, the manufacturing technology resources developed in the DOE's nuclear weapons complex and, with industry leadership and participation, to apply both DOE and industry technologies, as appropriate, to agile manufacturing demonstration projects. The program is DOE-funded, with matching industry participation and participation from NIST and other government agencies.

TEAM is divided into the following five "thrust areas:"

Product Design and Enterprise Concurrency -- design tools and approaches that speed the transition of designs to production

- Virtual Manufacturing -- modeling and simulation tools to evaluate and improve products and processes

- Manufacturing Planning and Control -tools for quick selection of resources, process optimization, process planning, numerical control, work instructions, scheduling and tracking

- Intelligent Closed-Loop Processing -advanced sensing and control technologies that provide rapid response

- Integration -- tools for communication and information transfer.

Methods, models, and software are to be identified in all of these areas and then tested and demonstrated on real products in three areas of application: material removal, sheet metal forming, and electronic/ electromechanical assembly. Primarily, TEAM will deploy existing technology, not undertake research and development, though it can be expected that application of the existing tools is apt to require development of interfaces.

\section{NIST Agile Manufacturing Projects}

Much NIST work contributes to rapid realization of high-quality product primarily through metrology and standards, so this work is a part of general agile manufacturing research and development. For example, quicker, more accurate measurement methods and improved process monitoring and control systems, as, e.g., the milling machine control study cited above (Rudder et al. 1992), contribute to industry agility.

At the virtual enterprise level of agility, NIST internal projects stem from its responsibilities in developing manufacturing applications of the National Information Infrastructure, stated in Bloom (1994) as: "Implementation of the NII concept for manufacturing will allow such capabilities as: (1) customers to "custom design" products, (2) companies to form alliances needed to produce new products (i.e., Agile Manufacturing), (3) small to medium size companies to interact with large companies for bidding on products (i.e., the Virtual Enterprise), (4) software system brokers to "rent" sophisticated manufacturing systems tools, and (5) rapid access to manufacturing knowledge by the product designers that will enable enterprises to use concurrent engineering practices." The NIST program pertaining to these objectives is the Systems Integration for Manufacturing Program (SIMA) which is focused on interface standards by which the communication and integration possibilities of the NII can be realized. SIMA has four program elements:

Manufacturing Systems Environment -models and software for integrating manufacturing systems 

Technology Transfer Environment -mechanisms for the exchange of information

Standards Development Environment -development of STEP (The Standard for Exchange of Product Model Data)

AMSANT Facility -- a testbed for advanced manufacturing systems and networking.

There could be a role for NIST statisticians in the design and analysis of tests of some advanced manufacturing systems, but I do not foresee much of a statistical role in the software and standards development activities which are the focus of SIMA. As noted above, though, at some point there will need to be statistical involvement in developing standards for the communication of statistical information pertaining to process capabilities.

NIST's Advanced Technology Program (ATP) funds a wide variety of industrial research, some of which is related to agile manufacturing. As an example, the most recent awards (November 1994) included one entitled "Rapid Agile Metrology for Manufacturing," which will develop a flexible, high-speed, high-accuracy measurement system. Agile and flexible are really not the same concepts, but one would have to get into the details of this project to see whether a distinction is being made in this case.

\section{A-PRIMED}

Sandia National Laboratories' A-PRIMED project was a demonstration project that actually produced hardware via an agile manufacturing approach. Conventional product realization (at Sandia and elsewhere) is geared toward producing a single product for a single customer, then doing the whole process over again for a different customer. The A-PRIMED approach is to design for and develop the ability to quickly produce any one of a family of electromechanical devices called discriminators for any customer whose requirements fall within a "parameter space" of possibilities. Thus, the limits of (rapid) customization are prescribed; requests outside of the bounds of the parameter space would not be turned away, but would have to be negotiated. Design, analysis, process development and characterization, and qualification activities were therefore geared toward the parameter space, not a single point design. A concurrent engineering approach was used to help assure that product design and production issues are identified early and a communication system was developed to facilitate transmittal of information among team members.

The component family developed by APRIMED is the "pin-in-maze" discriminator, a safety/security device that permits the transfer of energy only on receipt of a specific binary code. The correct code moves a pin through a maze and closes a switch; an incorrect code locks up the device. The device has to be quite robust to prevent unwanted closure of the switch in accident environments. Parameter variations considered for this family of components included the code length and pattern, mounting plate geometry, and part material. The goal was to be able to produce quickly a discriminator at any point in the (qualified) parameter space. For example, highly reliable operation of a discriminator requires very precise balancing of the maze wheel. Every different code changes the geometry of the maze wheel and thus requires a unique balancing (by removing material). The objective of A-PRIMED was to automatically translate any acceptable code 

into a maze wheel design and $\mathrm{NC}$ machining program so that the required maze wheel can be quickly produced without human intervention. Furthermore, robotic assembly instructions keyed to maze wheel features will also be automatically generated to permit prompt assembly of the fabricated parts.

For a parameter space with any breadth at all, or one that includes continuous parameters, adequate assurance that acceptable product can be realized throughout the parameter space cannot be obtained by fully realizing product at every point in the parameter space. And even if such brute force, exhaustive qualification could be economically done, that would defeat the purpose of agility. Rather, in any realistic context, tests and analyses can be conducted only at a subset of points in the parameter space, points selected to provide an engineering and statistical basis for inference to points not tested. For example, if tests and analyses show that the device can survive its shock requirements at certain extreme configurations included in the parameter space, then this provides assurance that it will also survive at intermediate configurations. Engineering understanding of the physics of the situation provides assurance that extremes and intermediates are correctly identified; statistical considerations will determine the level of assurance provided. Also, for the sake of economy and efficiency, the qualification focus is on constituent processes and subassemblies, rather than fully realized devices. For example, some machining processes, such as drilling a hole or cutting certain features, may be constant throughout the parameter space, so there is no need to repeatedly qualify them as other aspects of the design change. Diegert, et al. (1995) describes the qualification process and its implementation for A-PRIMED in detail.
Note that this project does not meet the broadest concepts of agility and agile manufacturing discussed in earlier sections. We (I was a participant) were not responding to unpredictable change; we had bounds and worked to assure predictability within those bounds. Any "totally new" device would have to fall within those bounds (though work done within defined bounds could provide a head start on meeting a request outside of the bounds). Also, reconfigurability is limited; we qualified one alternative machining facility and planned for both manual and robotic assembly. But, these limitations seem prudent and necessary. Paradigms do not shift overnight. Parameter-space thinking, in particular, has been difficult to adopt. Thinking in terms of possible future customers instead of the specific needs of the one you know can blur a team's focus. Lessons learned should contribute to much better understanding of the practice of agile manufacturing.

There is one reconfigurability issue that warrants some attention for virtual enterprises, in general: Many A-PRIMED team members were involved only parttime in the project. Thus, they plugged themselves into and out of the project at various times and the personnel associated with various functions changed over the life of the project. Thus, the connections in Fig. 1 come and go. Re-establishing connections takes time and can introduce variability. The well-designed virtual enterprise will have to address such issues.

Sandia statisticians were involved in developing the conceptual approach of the A-PRIMED project and then became responsible for leading the qualification activities. This level of involvement led to a variety of activities that a consulting specialist doesn't have to do, such as: scheduling meetings, taking and distributing minutes, tracking open items, 

reminding, coaxing, and wheedling. The parameter space qualification efforts became the prime way by which design and production interface issues were identified and coherently addressed. A myriad of "things happen" between the high-level concepts and goals of agile manufacturing and the actual production of functioning, highly-customized devices and the APRIMED history, if it is written, should be quite helpful in identifying the sorts of problems that can be encountered and in pointing toward solutions.

\section{Other Research}

The 1994 ORSA/TIMS (Operations Research and Management Science societies) conference included three sessions on agile manufacturing and several other papers on the topic. These presentations tended to deal with conceptual and infrastructural aspects of agile manufacturing. Modeling by the OR/MS community is primarily what I would call factory-level modeling, models that deal with tasks such as scheduling, provisioning, and transporting, rather than the physics of a manufacturing process. This sort of modeling would seem, therefore, to be quite appropriate to virtual enterprise modeling (and I would note that the TEAM project, discussed above, includes an enterprise modeling task). All the statistical issues pertaining to parameter estimation, validation, etc., discussed above for process models, also are pertinent in this case. Integrating process and enterprise models is the overall objective discussed above by Szekely and Trapaga (1994). Spring Research Conference (SRC) on Statistics in Industry and Technology, June 1994.

This conference, which I immodestly mention because of my familiarity with it as Program Chair, did not have any papers that addressed agile manufacturing per se, but there were numerous papers pertaining to the statistical aspects that have been discussed in this report. The conference illustrated the breadth of potential statistical opportunities for helping industry achieve more rapid, economical product realization and shows that the sorts of statistical participation called for in this report are occurring.

\section{CONCLUSION}

The goal of agile manufacturing -- quick, economical realization of high-quality, customized product -- is important to industrial competitiveness and survival. The routes to that goal may differ from industry to industry and company to company. That is the point of the scenarios in Nagel and Dove (1991). Common to all, though, is the need to provide information that can be readily used to decrease design and production time and cost and maintain and improve high quality. This report presents my perspective, which is concerned with statistical aspects of this information. Other perspectives, and particular technologies (electronic systems, mechanical assemblies, materials processing, ...), will raise many other issues. Concurrent, multi-disciplinary work will be required to translate general principles of agile manufacturing into successful production and delighted (or astonished) customers. Let's start now.

\section{ACKNOWLEDGMENTS}

My thanks go to Dick Schwoebel, Sandia, and Bob Lundegard, NIST, who encouraged and supported my participation in the NIST Research Fellowship program. I would also like to express my appreciation to Rick Dove of the Agility Forum and to members of the Agile Operations Focus Group for 

partially educating me on the topic of agility in manufacturing. Thanks also to Rodema Ashby, Sandia, and the APRIMED project team for providing additional opportunities to explore the role of statistics in agile manufacturing. The report benefited from reviews by Nien-Fan
Zhang, NIST; Sue Hartman, Resultant Manufacturing Services, and Kathleen Diegert, Chris Forsythe, and Joe Baxter, all of Sandia, and from discussions of computer experiments with Max Morris, Oak Ridge National Laboratory. 



\section{REFERENCES}

AGARD (Advisory Group for Aerospace Research \& Development) (1994) "A Selection of Experimental Test Cases for the Validation of CFD Codes," AGARD Advisory Report No. 303, printed by Canada Communication Group, 45 Sacre-Coeur Blvd., Hull (Quebec), Canada K1A 0S7.

Algeo, M. E. A. (1994) "A State-of-the-Art Survey of Methodologies for Representing Manufacturing Process Capabilities," NISTIR 5391, U.S. Department of Commerce, March 1994.

Bennett, H. S., and Lowney, J. R. (1994) "Physics for Device Simulations and its Verification by Measurements," Semiconductors, Part II, Springer-Verlag, ed. by Coughran, Cole, Lloyd, and White, 33-73.

Blakey, P. A. and Zirkle, T. E. (1994) "An Industrial Perspective on Semiconductor Technology Modeling," Semiconductors, Part II, Springer-Verlag, ed. by Coughran, Cole, Lloyd, and White, 75-88.

Bloom, H. M. (1994) "Technical Program Description Systems Integration for Manufacturing (SIMA)," NISTIR 5476, U.S. Department of Commerce, July 1994.

Cowger, G. L. (1994) "Manufacturing Matters," plenary presentation to ORSA/TIMS joint national meeting, Detroit, Oct. 24.

Crowder, S. V. (1992) "An SPC Model for Short Production Runs: Minimizing Expected Cost," Technometrics, 34, 64-73.

Diegert, K. V., et al. (1995) "Achieving Agility Through Parameter Space Qualification," presented at the 1995 Agility Forum.

Dove, R. (1994) "Tools for Analyzing and Constructing Agility," Agility Forum, Bethlehem, PA 18015.

Dove, R. (1995) "Introduction to the Agile Practice Reference Base: Challenge Models and Benchmarks," Agility Forum, Bethlehem, PA 18015.

Easterling, R. G. (1989) "Comment on Designs for Computer Experiments," Statistical Science, 4, 425-427.

Easterling, R. G. (1995) "Virtual Prediction of Process Capability," (in preparation).

Easterling, R. G., Mazumdar, M., Spencer, F. W., and Diegert, K. V. (1991) "System-Based Component-Test Plans and Operating Characteristics: Binomial Data," Technometrics, 33, $287-$ 298. 

Faltin, F., Runger, G. and Vandeven, M. (1994) "Set-Up control for Short Run Processes," presented at the Spring Research Conference on Statistics in Industry and Technology, June 13$15,1994$.

Goldman, S. L., ed., Benchmarking Agility, Iacocca Institute, Lehigh University, Bethlehem, PA 18015

Hilton, P. D. and Gill, G. K. (1994) "Achieving Agility: Lessons from the Leaders," Manufacturing Review, 7, 172-179.

Hoerl, R. W., Hooper, J. H., Jacobs, P. J., and Lucas, J. M. (1993) "Skills for Industrial Statisticians to Survive and Prosper in the Emerging Quality Environment," The American Statistician, 47 280-292.

$\mathrm{Hu}$, A. (1994) "Run-by-Run Control of Flexible Manufacturing Processes: A Bayesian Approach to Combining SPC and Feedback Control," presented at the Spring Research Conference on Statistics in Industry and Technology, June 13-15, 1994.

Jain, S. (1994) "Manufacturing Validation: A Key Enabler for Agile Manufacturing," presentation at ORSA/TIMS Detroit Conference, October, 1994.

Kacker, R. N. (1985) "Off-Line Quality Control, Parameter Design, and the Taguchi Method," Journal of Quality Technology, 17, 176-209.

Karr, A. F. (1994) Statistics and Materials Science, Technical Report \#4, National Institute of Statistical Sciences, P.O. Box 14162, Research Triangle Park, NC 27709

Konig, W. and Knop, M. (1992) "Methods for Predicting Process Behaviour in Grinding," Robotics \& Computer-Integrated Manufacturing, 9, 395-406.

McDonald, G. C. (1993) personal communication.

McKay, M. D., Conover, W. J., and Beckkman, R. J. (1979) "A Comparison of Three Methods for Selecting Values of Input Variables in the Analysis of Output From a Computer Code," Technometrics, 21, 239-245.

Meyyappan, M. (1994) Computational Modeling in Semiconductor Processing, Artech House, 685 Canton St., Norwood, MA 02062

Montgomery, D. C., Keats, J. B., Runger, G. C., and Messina, W. S. (1994) "Integrating Statistical Process Control and Engineering Process Control," Journal of Quality Technology, 26, 79-87.

Morris, M. D. (1994) "Some Recent Developments in the Design and Analysis of Computer Experiments and an Input Screening Example," NIST seminar presentation, Nov. 16.

Morris, M. D., Mitchell, T. J., and Ylvisaker, D. (1993) "Bayesian Design and Analysis of Computer Experiments: Use of Derivatives in Surface Prediction," Technometrics, 35 243-255. 

Morton, O. (1994) "Manufacturing Technology," The Economist, March 5, 1994, 3-18.

Nagel, R. N., and Dove, R. (1991) 21st Century Manufacturing Enterprise Strategy, Iacocca Institute, Lehigh University, Bethlehem, PA 18015

Nair, V. N. (1992) "Taguchi's Parameter Design: A Panel Discussion," Technometrics, 34, 127161.

Peters, T., and Waterman, R. H., Jr., (1982) In Search of Excellence, Harper and Row.

Quesenberry, C. P. (1991) "SPC Q Charts for Start-Up Processes and Short or Long Runs," Journal of Quality Technology, 23, 213-224.

Rudder, F., Guthrie, W., Filliben, J. (1992) "Methodology for Characterizing TemperatureRelated Positioning Errors of a Vertical Axis Milling Machine," NIST internal report.

Sacks, J. Welch, W. J., Mitchell, T. J., and Wynn, H. P. (1989) "Design and Analysis of Computer Experiments" (with discussion), Statistical Science, 4, 409-435.

Szekely, J. and Trapaga, G. (1994) "Some Perspectives on the Mathematical Modeling of Materials Processing Operations," Modelling and Simulation in Materials Science and Engineering, 2, 809-828.

TEAM Program Office (1994) "TEAM Strategic Plan, Books 1 and 2," Oak Ridge National Laboratory.

Vander Wiel, S. A., Tucker, W. T., Faltin, F. W., and Doganaksoy, N. (1992) "Algorithmic Statistical Process Control: Concepts and an Application," Technometrics, 34, 286-297.

Welch, W. J., Buck, R. J., Sacks, J., Wynn, Y. P., Mitchell, T. J., and Morris, M. D. (1992) "Screening, Predicting, and Computer Experiments," Technometrics, 34, 15-25.

Wong, W. T., Pan, J. Y-C., and Plummer, J. D. (1992) "Virtual Factory-Based Environment for Semiconductor Device Development," Proceedings of 1992 IEEE/SEMI International Semiconductor Manufacturing Science Symposium, 117-123.

Zhang, C. and Wang, H. (1993) "The Discrete Tolerance Optimization Problem," Manufacturing Review, 6, 60-71. 


